\title{
Radiative-convective equilibrium model intercomparison project
}

\author{
Allison A. Wing ${ }^{1}$, Kevin A. Reed ${ }^{2}$, Masaki Satoh $^{3}$, Bjorn Stevens $^{4}$, Sandrine Bony $^{5}$, and Tomoki Ohno ${ }^{6}$ \\ ${ }^{1}$ Florida State University, Tallahassee, FL, USA \\ ${ }^{2}$ Stony Brook University, Stony Brook, NY, USA \\ ${ }^{3}$ Atmosphere and Ocean Research Institute, The University of Tokyo, Kashiwa, Japan \\ ${ }^{4}$ Max Planck Institute for Meteorology, Hamburg, Germany \\ ${ }^{5}$ Laboratoire de Météorologie Dynamique, IPSL, CNRS, Paris, France \\ ${ }^{6}$ Japan Agency for Marine-Earth Science and Technology, Yokohama, Japan
}

Correspondence: Allison A. Wing (awing@fsu.edu)

Received: 29 August 2017 - Discussion started: 19 September 2017

Revised: 22 January 2018 - Accepted: 24 January 2018 - Published: 2 March 2018

\begin{abstract}
RCEMIP, an intercomparison of multiple types of models configured in radiative-convective equilibrium ( $\mathrm{RCE}$ ), is proposed. RCE is an idealization of the climate system in which there is a balance between radiative cooling of the atmosphere and heating by convection. The scientific objectives of RCEMIP are three-fold. First, clouds and climate sensitivity will be investigated in the RCE setting. This includes determining how cloud fraction changes with warming and the role of self-aggregation of convection in climate sensitivity. Second, RCEMIP will quantify the dependence of the degree of convective aggregation and tropical circulation regimes on temperature. Finally, by providing a common baseline, RCEMIP will allow the robustness of the RCE state across the spectrum of models to be assessed, which is essential for interpreting the results found regarding clouds, climate sensitivity, and aggregation, and more generally, determining which features of tropical climate a RCE framework is useful for. A novel aspect and major advantage of RCEMIP is the accessibility of the RCE framework to a variety of models, including cloud-resolving models, general circulation models, global cloud-resolving models, singlecolumn models, and large-eddy simulation models.
\end{abstract}

\section{Introduction}

Radiative-convective equilibrium (RCE) has long been used as an idealization of the climate system. In a greenhouse atmosphere, convection must balance the radiative heat loss of the atmosphere, making radiative-convective equilibrium the simplest possible description of the climate system (Dines, 1917). For this reason, there is a rich history of modeling RCE, mostly as a one-dimensional problem (e.g., Möller, 1963; Manabe and Strickler, 1964; Satoh and Hayashi, 1992; Renno et al., 1994). These early studies of RCE helped formulate an understanding of the basic characteristics of climate and the first estimates of climate sensitivity (Manabe and Wetherald, 1967; Ramanathan and Coakley, 1978; Charney et al., 1979). Early work with two-dimensional simulations of RCE studied the relationship between convection and environmental structures (Nakajima and Matsuno, 1988; Held et al., 1993; Sui et al., 1994; Randall et al., 1994; Grabowski et al., 1996). In recent years, as it became possible to perform more computationally intensive numerical simulations of RCE, there has been a revival in the use of RCE to study a variety of problems in tropical meteorology and climate. One common configuration is to simulate RCE with a three-dimensional numerical model with explicitly resolved convection over domain lengths of 100-1000 km (e.g., Tompkins and Craig, 1998; Bretherton et al., 2005). The RCE state is achieved by prescribing uniform solar insolation and a horizontally uniform boundary condition (constant sea surface temperature (SST) or a slab ocean model) and initializing the model with random noise. There is also a growing body of work employing RCE in general circulation models (GCMs) with parameterized clouds and convection (e.g., Held et al., 2007; Popke et al., 2013; Bony et al., 2016; Silvers et al., 2016).

The popularity of RCE arises from the fact that it remains the simplest way to phrase many important ques- 
tions about the climate system. RCE has been extensively used to help answer questions such as how the representation of subgrid-scale processes influences the coupling of clouds and convection to the climate system (e.g., Satoh and Matsuda, 2009; Becker et al., 2017), and how this coupling depends on temperature (e.g., Muller et al., 2011; Romps, 2011; Singh and O'Gorman, 2013, 2014, 2015; Seeley and Romps, 2015, 2016; Hohenegger and Stevens, 2016). RCE has been used to study the predictability of mesoscale rainfall (e.g., Islam et al., 1993), tropical anvil clouds (Bony et al., 2016; Cronin and Wing, 2017), and precipitation extremes (e.g., Muller et al., 2011; Romps, 2011; Muller, 2013; Singh and O'Gorman, 2014; Pendergrass et al., 2016), as well as how the land surface influences the climate state (Rochetin et al., 2014; Becker and Stevens, 2014), or the rectifying effects of surface heterogeneity in the form of islands (e.g., Cronin et al., 2015). RCE has also been used as a background state for tropical cyclone studies (e.g., Nolan et al., 2007; Chavas and Emanuel, 2014; Reed and Chavas, 2015). A central theme arising in many of these studies, and related to the formation of tropical cyclones (Wing et al., 2016) and the Madden-Julian Oscillation (Arnold and Randall, 2015; Satoh et al., 2016), is the role of convective aggregation, which often arises spontaneously in studies of RCE using explicit and parameterized convection (Wing et al., 2017, and references therein). It remains an open question as to how and whether the real atmosphere self-aggregates, and to what extent this is important for the properties of the climate system (Bony et al., 2015), in part because these aspects of the simulations appear sensitive to how the models are formulated (e.g., Muller and Held, 2012).

Assessing the structural sensitivity of simulations of RCE is hindered by the absence of a common baseline. Past studies differ in many, seemingly unessential details, which makes them hard to compare and determine which aspects of the simulations are robust. These range from different prescriptions of boundary conditions, such as incoming solar radiation, to different specifications of atmospheric composition, to different treatments of the upper atmosphere, or surface properties such as albedo. To provide context for the many studies that have been performed so far, and to provide a starting point for the many studies to come, a common baseline would be helpful. In this paper, we propose such a baseline in the form of a model intercomparison study, RCEMIP. A standard configuration of RCE is a useful framework for model development and evaluation (Held et al., 2007; Reed and Medeiros, 2016), but in addition to providing a fixed point for past and future studies, such an intercomparison can itself address important questions related to RCE, such as establishing which features of the RCE state are consistent across models and which vary across configurations. Already, groups are beginning to compare RCE solutions using general circulation models with parameterized physics on large domains, to simulations on smaller domains with finer grids, to solutions using cloud-resolving models (e.g., Hohenegger and Stevens, 2016). No other framework is accessible by so many of the varied models used to study the climate system, as in addition to cloud-resolving models, general circulation models, and single-column models, large-eddy simulation models and even Earth system models of intermediate complexity (Claussen et al., 2002) could be applied to the problem of RCE. Hence, through the definition of a common baseline, it should be possible to encourage the study of this canonical representation of the climate system using an even wider range of models, which is important for evaluating the generality of previous work on RCE. In addition to the simplicity and accessibility of the RCE framework, its importance lies in its similarities to substantial aspects of the real atmosphere; in general, RCE states are thought to correspond to convective regions over the tropical western Pacific warm pool, in terms of thermal structure (RCE has also been considered to represent the whole tropical belt, in which there is no large-scale vertical motion on average over the tropics and an approximate moist adiabatic thermal structure). There have already been some efforts to consider RCE simulations within a hierarchy of models; for example, Held et al. (2007) and Popke et al. (2013) compared cloud feedbacks between a GCM in a realistic configuration and in RCE, and Satoh et al. (2016) compared the structure of tropical convective systems between Earth-like aqua-planet experiments and RCE. A standard configuration of RCE would enable more of these types of comparisons.

Given this backdrop, in what follows, we describe the proposed model intercomparison study, RCEMIP, and more specifically detail the questions it will be used to address. In Sect. 2, we state the main scientific questions that this initiative will address. Subsequent sections specify the experimental design, including the required output and diagnostics. Finally, to give a flavor and better guide to those who wish to participate in this study, in Sect. 5, we present some sample results from three different models.

\section{Science objectives}

The three themes that RCEMIP has been designed for are as follows:

1. What is the response of clouds to warming and the climate sensitivity in RCE?

2. What is the dependence of convective aggregation and tropical circulation regimes on temperature in RCE?

3. What is the robustness of the RCE state, including the above results, across the spectrum of models?

The first theme of RCEMIP, clouds and climate sensitivity, is motivated by the fact that cloud feedbacks are the largest source of uncertainty in estimates of climate sensitivity and depend on processes that are largely parameterized in global 
climate models (e.g., Boucher et al., 2013). The role of convection in cloud feedbacks is central to a better understanding of global and regional climate changes, as pointed out by the WCRP Grand Challenge on Clouds, Circulation, and Climate Sensitivity (Bony et al., 2015). RCEMIP, which includes both cloud-resolving models (CRMs) and GCMs, is uniquely situated to determine the response of certain types of clouds to warming, without the complications of topography, latitudinal insolation gradients, and the associated dynamical disturbances. Recent work has suggested a thermodynamic mechanism for a decrease in anvil cloud fraction with warming in several GCMs (Bony et al., 2016) and a CRM (Cronin and Wing, 2017), but the robustness of this response across a wider range of models has yet to be determined. For example, one other CRM finds the opposite response, an increase in anvil cloud fraction with warming (Singh and O'Gorman, 2015). Changes in the amount and height of anvil clouds with warming have strong implications for cloud feedbacks, and the coupling between temperature, cloud amount, and circulation may contribute to a narrowing of convective areas - both of which could lead to a type of iris effect (Mauritsen and Stevens, 2015; Bony et al., 2016; Byrne and Schneider, 2016, 2018). The net feedback parameter of the RCE state may be computed, which is reminiscent of the use of single-column model simulations of RCE for the very first estimates of climate sensitivity, but now RCE can be simulated in much more advanced models that allow relative humidity and clouds to vary, including models that allow for the generation of large-scale circulations by self-aggregation. The climate sensitivity of RCE simulations would reflect the fundamental characteristics of each model's representation of tropical clouds and convection, as opposed to Coupled Model Intercomparison Project (CMIP)-type simulations, which include many additional complexities such as ice-albedo feedbacks and interactions between clouds and midlatitude baroclinic eddies. A potentially important factor in determining the climate sensitivity of RCE is the extent to which a given model's convection self-aggregates and how the aggregation changes with warming. Self-aggregation has been hypothesized to be important for climate and climate sensitivity (Khairoutdinov and Emanuel, 2010; Mauritsen and Stevens, 2015) because both numerical simulations (e.g., Bretherton et al., 2005) and observational analyses (e.g., Tobin et al., 2013) indicate the mean atmospheric state is drier and more efficient at radiating heat to space when convection is more aggregated. Much remains to be understood, however, about how the self-aggregation in idealized simulations is borne out in the real atmosphere (Holloway et al., 2017). The role of selfaggregation in climate is therefore an aspect of climate sensitivity that RCEMIP will target.

The manner and extent to which self-aggregation is temperature dependent is strongly related to the impact of aggregation on climate sensitivity but remains unresolved (Wing and Emanuel, 2014; Emanuel et al., 2014; Wing and Cronin,
2016; Coppin and Bony, 2015; Bony et al., 2016; Cronin and Wing, 2017). Therefore, the second theme of RCEMIP is about the dependence of the degree of convective selfaggregation on temperature (for instance, whether convection becomes more or less aggregated in a warmer climate). Not only does the degree of self-aggregation have implications for climate feedbacks, changing convective organization has also been shown to be one mechanism for increases in extreme precipitation with warming (Pendergrass et al., 2016). Changes in the amount of organized convection have also been linked to observed regional tropical precipitation increases (Tan et al., 2015). In addition, the fact that self-aggregation generates large-scale overturning circulations allows us to ask the more general question of how tropical circulation regimes change with climate. In CRMs with domain geometries capable of containing multiple selfaggregated regions, there is the additional possibility of examining interactions between clouds, convection, and circulation in a framework that explicitly simulates both convection and the large-scale circulation in which it is embedded, which is a rare combination (Cronin and Wing, 2017). Across both CRMs and GCMs, RCEMIP will be able to assess how circulation strength depends on temperature.

The final theme of RCEMIP, and the most critical, is the robustness of the RCE state, its changes with warming, and representation of self-aggregation across the spectrum of models. The broader implications of the results from the first two themes, regarding clouds and aggregation, depend in part on our ability to establish a consistent picture of the RCE state; identifying which features and responses are robust across models is essential. The evaluation of the robustness of the RCE state should include a comparison of baseline characteristics, such as profiles of humidity and cloudiness and the radiative cooling rate and mean surface precipitation rate at which equilibrium is reached, but could have a more lasting impact on theories of tropical climate by also including a determination of the universality of theoretical invariances or relationships found in a single model. For example, relative humidity has been argued to be a function of temperature only by Romps (2014) and radiative flux divergence has been found to be a nearly universal function of temperature (Ingram, 2010; Jeevanjee and Romps, 2017; Cronin and Wing, 2017). Such invariances could simplify thinking about the response of RCE, and perhaps the actual tropics, to warming, but there is a lack of understanding of their robustness across models. In addition, a comparison of the inter-model spread in climate sensitivity of the RCE simulations with the inter-model spread of CMIP6 simulations would be informative. Despite the simplicity of the RCE setup, there is the potential for a wide range of behavior given how essential clouds and convective processes are to determining the RCE state, and the myriad of different ways these processes are represented in models. Further, while multiple common features and mechanisms have emerged across different studies of self-aggregation (Wing et al., 2017), the behavior of self- 
aggregation of convection across a wide range of models set up in a consistent manner has not been fully characterized. RCEMIP will enable us to better determine the robustness of self-aggregation and its sensitivities, an important step to understanding its role in climate.

\section{Simulation design}

The experimental design of RCEMIP is to require a small set of experiments that are designed to maximize the utility of the RCEMIP simulations in answering the questions about clouds, climate sensitivity, and self-aggregation posed above while minimizing the effort required by the modeling groups.

\subsection{Required simulations}

We propose the following two sets of simulations to form the basis of RCEMIP, each to be performed at three different values of uniform, fixed SSTs:

1. RCE_small: RCE simulation on a small, square domain (for CRMs) or single column (for GCMs).
a. RCE_smal1295: uniform, fixed SST of $295 \mathrm{~K}$.
b. RCE_smal1300: uniform, fixed SST of $300 \mathrm{~K}$.
c. RCE_smal1305: uniform, fixed SST of $305 \mathrm{~K}$.

2. RCE_large: RCE simulation on a large, rectangular domain (for CRMs) or global (for GCMs).
a. RCE_large2 95: uniform, fixed SST of $295 \mathrm{~K}$.
b. RCE_large 300 : uniform, fixed SST of $300 \mathrm{~K}$.
c. RCE_large 305: uniform, fixed SST of $305 \mathrm{~K}$.

The domain specifications are provided in Sect. 3.3. RCE_small will serve as a spin-up simulation for RCE_large (see Sect. 3.2.3) but will also serve as a control simulation that represents "conventional" RCE without convective self-aggregation (which might occur in RCE_large). The surface temperatures for these simulations have been chosen so that RCEMIP spans a relatively wide range $(10 \mathrm{~K})$ of SST near the current climate with a limited number of simulations. Additional, optional simulations at intermediate SSTs or warmer or cooler SSTs could be performed by modeling groups if desired. Models with parameterized convection with the capability also have the option of performing RCE_small and RCE_large on planar domains.

\subsection{RCE setup}

RCE is simulated in a modeling setting by imposing a homogeneous lower boundary representing the thermodynamic state of a sea surface with a fixed (i.e., spatially uniform) temperature and spatially uniform insolation as a forcing. The
Table 1. Geophysical constants.

\begin{tabular}{ll}
\hline Parameter & Value \\
\hline Earth rotation rate & $\Omega=0$ \\
Coriolis parameter & $f=0$ \\
Mean Earth radius & $R_{\mathrm{E}}=6371.0 \mathrm{~km}$ \\
Mean surface gravity & $g=9.79764 \mathrm{~ms}^{-2}$ \\
Gas constant for dry air & $R_{\mathrm{d}}=287.04 \mathrm{~J} \mathrm{~kg}^{-1} \mathrm{~K}^{-1}$ \\
Specific heat capacity for dry air & $C_{p \mathrm{~d}}=1004.64 \mathrm{~J} \mathrm{~kg}^{-1} \mathrm{~K}^{-1}$ \\
Water vapor gas constant & $R_{\mathrm{V}}=461.50 \mathrm{~J} \mathrm{~kg}^{-1} \mathrm{~K}^{-1}$ \\
Water vapor specific heat capacity & $C_{p \mathrm{v}}=1846.0 \mathrm{~J} \mathrm{~kg}^{-1} \mathrm{~K}^{-1}$ \\
Latent heat of vaporization at $0^{\circ} \mathrm{C}$ & $L_{\mathrm{v} 0=2.501 \times 10^{6} \mathrm{~J} \mathrm{~kg}^{-1}}$ \\
Latent heat of fusion at $0^{\circ} \mathrm{C}$ & $L_{\mathrm{f} 0}=3.337 \times 10^{5} \mathrm{~J} \mathrm{~kg}^{-1}$ \\
Latent heat of sublimation at $0^{\circ} \mathrm{C}$ & $L_{\mathrm{s} 0}=2.834 \times 10^{6} \mathrm{~J} \mathrm{~kg}^{-1}$ \\
\hline
\end{tabular}

model is initialized with the same temperature and moisture sounding at every grid point and zero wind, and convection is generated by prescribing some symmetry-breaking random noise. The model is then run to stationarity, at which time irradiances, precipitation, and other variables have stopped trending up or down and exhibit variability about an approximately constant value. Here, we consider RCE in a nonrotating setting; i.e., the Coriolis parameter, $f$, or Earth's angular velocity, $\Omega$, is zero. Recommendations for geophysical constants and parameters are given in Table 1; models should use standard Earth values, following the convention of the Aqua-Planet Experiment (APE; http://climate.ncas.ac. uk/ape/design.html).

\subsubsection{Surface boundary condition}

The lower boundary condition is to be a spatially uniform, fixed sea surface temperature. If a skin temperature equation is employed, the skin temperature should be equal to the prescribed surface temperature. There is no sea ice and no land.

The surface enthalpy fluxes are to be calculated interactively from the resolved surface wind speed and air-sea enthalpy disequilibrium. Models should compute surface exchange coefficients following their normal formulation, for instance, implying stability corrections, gustiness parameterizations, or sea-state-dependent roughness formulations as is standard for their model tropics. If allowed by a model's surface layer formulation, a minimum wind speed of $1 \mathrm{~ms}^{-1}$ should be enforced (either as $V=\max \left(V_{\text {resolved }}, 1\right)$ or in quadrature as $V=\sqrt{V_{\text {resolved }}^{2}+1}$. We recognize that biases may result from the lack of boundary layer closure in some CRMs, but here we ask models to simply use their standard boundary layer scheme, if one exists.

\subsubsection{Radiative processes}

The shortwave and longwave radiative heating rates are to be calculated interactively from the modeled state using a radia- 
Table 2. Radiation and initialization parameters.

\begin{tabular}{ll}
\hline Parameter & Value \\
\hline Radiation parameters & \\
\hline $\mathrm{CO}_{2}$ concentration & $348 \mathrm{ppmv}$ \\
$\mathrm{CH}_{4}$ concentration & $1650 \mathrm{ppbv}$ \\
$\mathrm{N}_{2} \mathrm{O}$ concentration & $306 \mathrm{ppbv}$ \\
CFC11 concentration & 0 \\
CFC12 concentration & 0 \\
CFC22 concentration & 0 \\
CCL4 concentration & 0 \\
$\mathrm{O}_{3}$ fit parameter $g_{1}$ & $3.6478 \mathrm{ppmv} \mathrm{hPa}^{-g_{2}}$ \\
$\mathrm{O}_{3}$ fit parameter $g_{2}$ & 0.83209 \\
$\mathrm{O}_{3}$ fit parameter $g_{3}$ & $11.3515 \mathrm{hPa}^{-2}$ \\
Solar constant & $551.58 \mathrm{~W} \mathrm{~m}^{-2}$ \\
$\mathrm{Zenith}$ angle & $42.05^{\circ}$ \\
Surface albedo & 0.07 \\
\hline Analytic sounding parameters & \\
\hline$z_{\mathrm{t}}$ & $15 \mathrm{~km}^{\circ}$ \\
$q_{0,295}$ & $12.00 \mathrm{~g} \mathrm{~kg}^{-1}$ \\
$q_{0,300}$ & $18.65 \mathrm{~g} \mathrm{~kg}^{-1}$ \\
$q_{0,305}$ & $24.00 \mathrm{~g} \mathrm{~kg}^{-1}$ \\
$q_{\mathrm{t}}$ & $10^{-11} \mathrm{~g} \mathrm{~kg}^{-1}$ \\
$z_{\mathrm{q} 1}$ & $4000 \mathrm{~m}$ \\
$z_{\mathrm{q} 2}$ & $7500 \mathrm{~m}$ \\
$p_{0}$ & $0.0067 \mathrm{~K} \mathrm{~m}^{-1}$ \\
\hline & $1014.8 \mathrm{hPa}^{-1}$ \\
\hline
\end{tabular}

tion scheme. GCMs that participate in CMIP6 (Eyring et al., 2016) should use the same radiation scheme as in CMIP6.

The climatologies of trace gases are to be adjusted so that they do not have any longitudinal and latitudinal dependencies, and their values should be fixed according to Table 2 . The $\mathrm{CO}_{2}$ concentration is to be set to $348 \mathrm{ppmv}, \mathrm{CH}_{4}$ is to be $1650 \mathrm{ppbv}$, and $\mathrm{N}_{2} \mathrm{O}$ is to be $306 \mathrm{ppbv}$, following the convention of the APE (http://climate.ncas.ac.uk/ape/design.html). Chlorofluorocarbon (CFC) concentrations are to be set to zero (following Popke et al., 2013). The ozone climatology is to be an analytic approximation of the horizontally uniform equatorial profile derived from the Aqua-Planet Experiment ozone climatology (Eq. 1, Fig. 1). The ozone volumetric mixing ratio, in units of parts per million, is to be computed from pressure using a gamma distribution:

$\mathrm{O}_{3}=g_{1} \times p^{g_{2}} \exp \left(-p / g_{3}\right)$,

where $g_{1}=3.6478, g_{2}=0.83209, g_{3}=11.3515, p$ is in $\mathrm{hPa}$, and $\mathrm{O}_{3}$ is in ppmv.

Aerosol effects are to be ignored by zeroing the aerosol concentrations. In some GCMs, aerosol effects may be ignored by excluding aerosol from the radiative transfer calculation and fixing the cloud droplet number concentration (we suggest $N_{\mathrm{c}}=1.0 \times 10^{8} \mathrm{~m}^{-3}$ ) and ice crystal number concentration (we suggest $N_{\mathrm{i}}=1.0 \times 10^{5} \mathrm{~m}^{-3}$ ) within the mi-
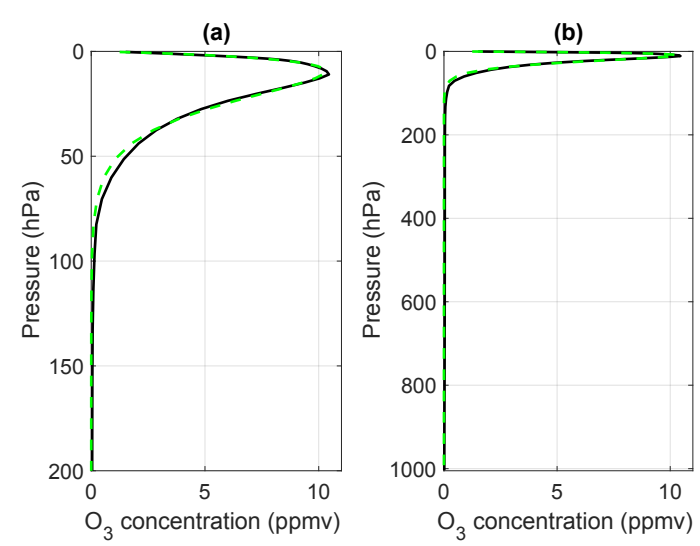

Figure 1. Ozone concentration (ppm) from the Aqua-Planet Experiment (black) and gamma distribution given by Eq. (1) (green dashes), as a function of pressure above $200 \mathrm{hPa}$ (a) and as a function of pressure over the whole atmosphere (b).

crophysics parameterizations, following Reed et al. (2015). Cloud optical properties should be determined by the microphysics parameterization. If specification of number concentrations or condensation nuclei is required (as in two-moment schemes), GCMs should use the aqua-planet configuration of their microphysics. For those models that do not have an aqua-planet configuration (i.e., CRMs), if the microphysics scheme uses fixed cloud droplet and ice crystal number concentration, we recommend these be set to the above values $\left(N_{\mathrm{c}}\right.$ and $\left.N_{\mathrm{i}}\right)$. For those schemes that instead specify cloud condensation nuclei (CCN) and ice nuclei (IN), or CCN and IN sources, they should set values consistent with the above specifications of $N_{\mathrm{c}}$ and $N_{\mathrm{i}}$.

Importantly, the incoming solar radiation is to be adjusted such that every model grid point sees the same incident radiation. It is to be spatially uniform and constant in time; there is to be no diurnal cycle and no seasonal cycle. A reduced solar constant of $551.58 \mathrm{~W} \mathrm{~m}^{-2}$ and a fixed zenith angle of $42.05^{\circ}$ should be used (Table 2); these values yield an insolation of $409.6 \mathrm{~W} \mathrm{~m}^{-2}$, equal to the tropical $\left(0-20^{\circ}\right)$ annual mean. The zenith angle is equal to the average insolation-weighted zenith angle between the Equator and $20^{\circ}$ (see Cronin, 2014). The surface albedo is to be fixed at a value of 0.07 , corresponding to its insolation-weighted globally averaged value. As an aside, we note that if simulations with interactive surface temperature are done in the future, an implied ocean heat transport ("Q-flux") will need to be applied to prevent a runaway greenhouse effect with this value of insolation. A formulation that adjusts for heat export through the ocean is preferred to one that reduces the solar constant to mimic the combined heat transport of the ocean and atmosphere because this is believed to better represent the competition between longwave cooling and water vapor absorption in the lower troposphere. 


\subsubsection{Initialization procedure}

RCE_large, the large domain/global set of simulations, is to be initialized from the horizontally averaged equilibrium sounding of the corresponding RCE_small small-domain/single-column simulation. We request that RCE_small be initialized with the below analytic moisture (Eq. 2), temperature (Eq. 4) and pressure (Eq. 5) profile, and zero wind. The analytic sounding approximates the moist tropical sounding of Dunion (2011), enabling the use of an observed sounding while eliminating the need for interpolation to different vertical grids. The parameter values for the analytic profile are found in Table 2 . The analytic initial specific humidity profile $q(z)$ is given, as a function of height (z) as

$q(z)=q_{0} \exp \left(-\frac{z}{z_{\mathrm{q} 1}}\right) \exp \left[-\left(\frac{z}{z_{\mathrm{q} 2}}\right)^{2}\right]$ for $0 \leq z \leq z_{\mathrm{t}}$

$q(z)=q_{\mathrm{t}}$ for $z>z_{\mathrm{t}}$,

where $z_{\mathrm{t}}=15 \mathrm{~km}$ approximates the tropopause height as seen in the Dunion (2011) sounding; $q_{0}$ is the specific humidity at the surface $(z=0 \mathrm{~km})$, which is taken to be $12 \mathrm{~g} \mathrm{~kg}^{-1}$ for the simulation at $295 \mathrm{~K}, 18.65 \mathrm{~g} \mathrm{~kg}^{-1}$ for the simulation at $300 \mathrm{~K}$, and $24 \mathrm{~g} \mathrm{~kg}^{-1}$ for the simulation at $305 \mathrm{~K}$; and $q_{\mathrm{t}}$ is the specific humidity in the upper atmosphere set to a constant value of $10^{-11} \mathrm{~g} \mathrm{~kg}^{-1}$. The values of $q_{0}$ have been adjusted so that the relative humidity is near $80 \%$ in the lower atmosphere for each SST value. The constant $z_{q 1}$ is set to $4000 \mathrm{~m}$ and the constant $z_{q 2}$ is set to $7500 \mathrm{~m}$. The analytic initial virtual temperature profile is given by

$T_{\mathrm{v}}(z)=T_{\mathrm{v} 0}-\Gamma z$ for $0 \leq z \leq z_{\mathrm{t}}$

$T_{\mathrm{v}}(z)=T_{\mathrm{vt}}$ for $z>z_{\mathrm{t}}$,

where the virtual temperature at the surface $T_{\mathrm{v} 0}=$ $T_{0}\left(1+0.608 q_{0}\right)$, the virtual temperature lapse rate $\Gamma$ is $0.0067 \mathrm{~K} \mathrm{~m}^{-1}$, and the virtual temperature in the upper atmosphere is the constant $T_{\mathrm{vt}}=T_{\mathrm{v} 0}-\Gamma z_{\mathrm{t}} . T_{0}$ is to be set to the SST value for each simulation $(295,300$, or $305 \mathrm{~K}$, respectively). The analytic initial temperature profile $T(z)$ is thus

$T(z)=\frac{T_{\mathrm{v}}(z)}{1+0.608 q(z)}$.

The initial pressure profile $p(z)$ is computed using the hydrostatic equation and ideal gas law:

$$
\begin{aligned}
& p(z)=p_{0}\left(\frac{T_{\mathrm{v} 0}-\Gamma z}{T_{\mathrm{v} 0}}\right)^{g /\left(R_{\mathrm{d}} \Gamma\right)} \text { for } 0 \leq z \leq z_{\mathrm{t}} \\
& p(z)=p_{\mathrm{t}} \exp \left(-\left[\frac{g\left(z-z_{\mathrm{t}}\right)}{R_{\mathrm{d}} T_{\mathrm{vt}}}\right]\right) \text { for } z>z_{\mathrm{t}},
\end{aligned}
$$

where

$p_{\mathrm{t}}=p_{0}\left(\frac{T_{\mathrm{vt}}}{T_{\mathrm{v} 0}}\right)^{g /\left(R_{\mathrm{d}} \Gamma\right)}$ and where $p_{0}$ is the surface pressure $1014.8 \mathrm{hPa}$, and $R_{\mathrm{d}}$ and $g$ are given in Table 1 . Code to compute this sounding from a specified set of height or pressure levels is provided on the RCEMIP website (http://myweb.fsu.edu/awing/rcemip. html). This analytic sounding shown in Fig. 2 is to be used only to begin the small-domain/single-column model simulations (RCE_small), not the large-domain/global simulations (RCE_large). It is worth nothing that this analytic setup is similar to that from Reed and Jablonowski (2011) used to initialize tropical environments in GCMs.

RCE_large, the large-domain/global simulations, should be initialized with average equilibrium profiles from the RCE_small simulations (at the corresponding SST). These equilibrium profiles should be derived by taking a horizontal and time mean of the RCE_small simulations, over the last 30 days of the 100-day simulation (i.e., after the simulation has reached statistical equilibrium). By starting from an equilibrium profile from the more computationally efficient RCE_small simulations, each RCE_large simulation will begin from that model's own RCE state and thus eliminate the necessity of a lengthy spin-up period with large adjustments. Self-aggregation (which can be thought of as the instability of the RCE state; Emanuel et al., 2014) would be manifest as a large divergence away from the initial state. Care should be taken to ensure the settings of the RCE_small simulations match those of the RCE_large simulations.

For both RCE_small and RCE_large, symmetry is to be broken by prescribing a small amount of thermal noise in the five lowest layers (an amplitude of $0.1 \mathrm{~K}$ in the lowest layer, decreasing linearly to $0.02 \mathrm{~K}$ in the fifth layer). This will allow convection to start within the first few hours of each simulation.

We note that this procedure implies that stratospheric water vapor will be initialized with very small, but non-zero, specific humidities. It is unlikely that the stratospheric water vapor will be properly equilibrated by the end of the RCEMIP simulations, and so it is possible that this could affect the sensitivity of radiative fluxes to warming. The stratospheric water vapor will thus need to be monitored and assessed in the evaluation of the simulations.

\subsection{Model-type specific settings}

The RCE setup described above is to be employed across all models, but we recognize that the domain and numerical details will necessarily be different between CRMs and GCMs, which we describe below. CRMs will employ a limited area planar domain, while GCMs will run on the sphere. We encourage modeling groups (with the capability) to simulate both RCE on the sphere and on the plane, which will help bridge the gap between CRMs and GCMs. Global cloudresolving models (GCRMs) are an additional model type that may participate in RCEMIP and represent an important midpoint between CRMs and GCMs. Participation of single- 


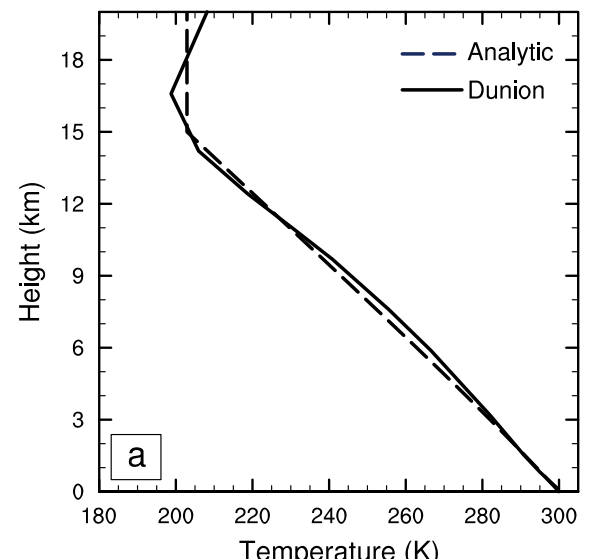

Table 3. CRM vertical grid for scalar variables.

\begin{tabular}{lrrrrc}
\hline Level & $\begin{array}{r}\text { Height } \\
(\mathrm{m})\end{array}$ & Level & $\begin{array}{r}\text { Height } \\
(\mathrm{m})\end{array}$ & $\begin{array}{c}\text { Level } \\
\text { Height } \\
(\mathrm{m})\end{array}$ \\
\hline 1 & 37 & 26 & 9000 & 51 & 21500 \\
2 & 112 & 27 & 9500 & 52 & 22000 \\
3 & 194 & 28 & 10000 & 53 & 22500 \\
4 & 288 & 29 & 10500 & 54 & 23000 \\
5 & 395 & 30 & 11000 & 55 & 23500 \\
6 & 520 & 31 & 11500 & 56 & 24000 \\
7 & 667 & 32 & 12000 & 57 & 24500 \\
8 & 843 & 33 & 12500 & 58 & 25000 \\
9 & 1062 & 34 & 13000 & 59 & 25500 \\
10 & 1331 & 35 & 13500 & 60 & 26000 \\
11 & 1664 & 36 & 14000 & 61 & 26500 \\
12 & 2055 & 37 & 14500 & 62 & 27000 \\
13 & 2505 & 38 & 15000 & 63 & 27500 \\
14 & 3000 & 39 & 15500 & 64 & 28000 \\
15 & 3500 & 40 & 16000 & 65 & 28500 \\
16 & 4000 & 41 & 16500 & 66 & 29000 \\
17 & 4500 & 42 & 17000 & 67 & 29500 \\
18 & 5000 & 43 & 17500 & 68 & 30000 \\
19 & 5500 & 44 & 18000 & 69 & 30500 \\
20 & 6000 & 45 & 18500 & 70 & 31000 \\
21 & 6500 & 46 & 19000 & 71 & 31500 \\
22 & 7000 & 47 & 19500 & 72 & 32000 \\
23 & 7500 & 48 & 20000 & 73 & 32500 \\
24 & 8000 & 49 & 20500 & 74 & 33000 \\
25 & 8500 & 50 & 21000 & & \\
\hline & & & & &
\end{tabular}

\subsubsection{CRMs}

For all experiments, CRM simulations, that is, model simulations with explicit convection run on a limited-area planar domain, are to employ a three-dimensional domain with doubly periodic lateral boundary conditions. The RCE_small simulations are to employ a square domain of $\sim 100 \mathrm{~km}$ length in each horizontal dimension and a horizontal grid spacing of $\sim 1 \mathrm{~km}$, which approximates the size of a GCM grid box.

The RCE_large simulations are to use a horizontal grid spacing of $\sim 3 \mathrm{~km}$ to resolve deep convection and cloud systems but reduce the computational cost. An elongated channel geometry of $\sim 6000 \mathrm{~km}$ in the zonal direction and $\sim 400 \mathrm{~km}$ in the meridional direction (an aspect ratio of approximately $16: 1$ ) will allow for the possibility of multiple convectively active regions (if the convection selfaggregates) and the development of large-scale circulations while still simulating three-dimensional convection. Selfaggregation is sensitive to domain size and other numerical details in square geometries (Muller and Held, 2012) but may be more robust in domains with elongated geometries (Wing and Cronin, 2016); this will make comparison across models easier. 
The vertical grid will be stretched with at least 74 vertical levels with a model top no lower than $33 \mathrm{~km}$ and a sponge layer in the top model layers to damp gravity waves, following a given model's usual prescription. Table 3 indicates the recommended vertical grid. The simulations should be run for at least 100 days.

\subsubsection{GCMs}

GCMs, that is, models with parameterized convection, should first be run in single-column mode for RCE_small, from which the equilibrium profile used to initialize the $\mathrm{RCE}$ _large global simulations is derived.

For RCE_large, GCM simulations should employ a three-dimension spherical global domain using whichever dynamical core and grid are standard for each given model. Each model should use the horizontal resolution, vertical coordinate, and grid of one of their CMIP6 configurations. The simulations should be run for at least 3 years $(\sim 1000$ days). If the GCM has the capability to run in a planar configuration, it should also be run on the CRM grid described in Sect. 3.3.1 but with the GCM grid spacing and physics parameterizations.

\subsubsection{GCRMs}

GCRMs, or models with explicit convection run on a nonrotating sphere, are an important category bridging CRMs and GCMs. Ideally, GCRMs should be run with the same grid spacing as CRMs and the same domain size as GCMs (that is, $\sim 3 \mathrm{~km}$ resolution and the real Earth radius $R_{\mathrm{E}}$, respectively). Although recently more computer resources have become available for running GCRMs at such resolutions, we opt to define a more moderate specification of GCRM experiments such that more research groups running GCRMs are able to join RCEMIP. We propose two options: GCRM1, arbitrary horizontal resolution for the sphere with the Earth's radius; and GCRM2, $\sim 3 \mathrm{~km}$ horizontal grid spacing for an arbitrary radius of the sphere. Required integration time is the same as that of CRMs (100 days), and the other settings are also the same as those of CRMs or GCMs, as appropriate.

In practice, relatively coarser resolutions than $3 \mathrm{~km}$ are used from GCRMs, though the resolution required to "resolve" clouds explicitly is ambiguous. Resolutions of 7 and $14 \mathrm{~km}$ are frequently used for the Nonhydrostatic ICosahedral Atmospheric Model (NICAM), and even coarser resolutions have been used without convective parameterizations in NICAM (Yoshizaki et al., 2012; Takasuka et al., 2015) and other models (e.g., Webb et al., 2015; Becker et al., 2017). In addition, the definition of the horizontal resolution depends on grid structure and details of discretization which vary among GCRMs, so we recognize that it may not be possible for all groups to use precisely the same resolution. If a smaller Earth radius is used, it can be $R_{\mathrm{E}} / 2, R_{\mathrm{E}} / 4, R_{\mathrm{E}} / 8$, or $R_{\mathrm{E}} / 16$ and so on (about $3200,1600,800$, or $400 \mathrm{~km}$, respec- tively). The reduction of the Earth's radius for global RCE studies has also been used in GCMs at hydrostatic scales (Reed and Medeiros, 2016).

The GCRM RCE_large simulations should be initialized from a non-aggregated state, which can be obtained either from a simulation on a much smaller horizontal domain (i.e., less than $200 \mathrm{~km}$ ) or a simulation with horizontally homogenized radiative heating rates. We encourage GCRM groups to contact the RCEMIP organizers to discuss appropriate model setups and coordinate with other groups.

\subsubsection{SCMs}

SCMs, or models with parameterized convection and a single grid column (no circulation), should be initialized using the analytic sounding described in Sect. 3.2.3 and should use whatever vertical grid is standard. If run in tandem with a parent GCM, care should be taken to ensure the settings and parameterizations are the same as in the global model. The simulations should be run for at least 3 years ( $\sim 1000$ days). While SCM simulations are not able to address questions about convective aggregation itself, they may be compared to a parent GCM to determine the impact of convective aggregation on the RCE state (should aggregation occur in the global model). SCM simulations may also be compared to the other RCE_small simulations (that is, to other SCMs and to non-aggregated small-domain CRM or LES simulations) to determine the robustness of the RCE state and the effectiveness of the SCM convective parameterization.

\subsubsection{LES}

LES, that is, models with explicit convection and subkilometer grid spacings that resolve the energy containing "large" turbulent eddies, may participate in RCEMIP by providing a set of 50-day simulations on a small square domain of $\sim 100 \mathrm{~km}$ length in each horizontal dimension with a horizontal grid spacing of $\sim 50-100 \mathrm{~m}$ and $\sim 100$ vertical levels. The setup is similar to the CRM setup except any boundary layer parameterization should be turned off and any LES subgrid model should be turned on. The LES model may be initialized from the analytic sounding provided in Sect. 3.2.1, so that it can be compared to the corresponding RCE_small at $\sim 1 \mathrm{~km}$ grid spacing. We encourage LES modelers to contact the RCEMIP organizers to discuss appropriate model setups and facilitate coordination with other groups.

\section{Output specification}

We request output following the conventions of CMIP6 (see http://clipc-services.ceda.ac.uk/dreq/index.html for variable descriptions). If possible, the output should be "CMORized", such that the output variable names and units are the same as in CMIP6. All variables should be saved for the entirety of each RCE_small and RCE_large simulation. 
Table 4. The 1-D hourly-averaged variables $(z, t)$ or $(t)$. TOA indicates the top of atmosphere.

\begin{tabular}{|c|c|c|}
\hline Variable name & Description & Units \\
\hline ta_avg & domain avg. air temperature profile & $\mathrm{K}$ \\
\hline ua_avg & domain avg. eastward wind profile & $\mathrm{ms}^{-1}$ \\
\hline va_avg & domain avg. northward wind profile & $\mathrm{ms}^{-1}$ \\
\hline hus_avg & domain avg. specific humidity profile & $\mathrm{kg} \mathrm{kg}^{-1}$ \\
\hline hur_avg & domain avg. relative humidity profile & $\%$ \\
\hline clw_avg & domain avg. mass fraction of cloud liquid water profile & $\mathrm{kg} \mathrm{kg}^{-1}$ \\
\hline cli_avg & domain avg. mass fraction of cloud ice profile & $\mathrm{kg} \mathrm{kg}^{-1}$ \\
\hline plw_avg & domain avg. mass fraction of precipitating liquid water profile & $\mathrm{kg} \mathrm{kg}^{-1}$ \\
\hline pli_avg & domain avg. mass fraction of precipitating ice profile & $\mathrm{kg} \mathrm{kg}^{-1}$ \\
\hline theta_avg & domain avg. potential temperature profile & $\mathrm{K}$ \\
\hline thetae_avg & domain avg. equivalent potential temperature profile & $\mathrm{K}$ \\
\hline tntrs_avg & domain avg. shortwave radiative heating rate profile & $\mathrm{Ks}^{-1}$ \\
\hline tntrl_avg & domain avg. longwave radiative heating rate profile & $\mathrm{Ks}^{-1}$ \\
\hline tntrscs_avg & domain avg. shortwave radiative heating rate profile - clear sky & $\mathrm{Ks}^{-1}$ \\
\hline tntrlcs_avg & domain avg. longwave radiative heating rate profile - clear sky & $\mathrm{Ks}^{-1}$ \\
\hline cldfrac_avg & global cloud fraction profile & $\%$ \\
\hline pr_avg & domain avg. surface precipitation rate & $\mathrm{kg} \mathrm{m}^{-2} \mathrm{~s}^{-1}$ \\
\hline hfls_avg & domain avg. surface upward latent heat flux & $\mathrm{Wm}^{-2}$ \\
\hline hfss_avg & domain avg. surface upward sensible heat flux & $\mathrm{Wm}^{-2}$ \\
\hline prw_avg & domain avg. water vapor path & $\mathrm{kg} \mathrm{m}^{-2}$ \\
\hline clwvi_avg & domain avg. condensed water path & $\mathrm{kg} \mathrm{m}^{-2}$ \\
\hline clivi_avg & domain avg. ice water path & $\mathrm{kg} \mathrm{m}^{-2}$ \\
\hline spwr_avg & domain avg. saturated water vapor path & $\mathrm{kg} \mathrm{m}^{-2}$ \\
\hline rlds_avg & domain avg. surface downwelling longwave flux & $\mathrm{Wm}^{-2}$ \\
\hline rlus_avg & domain avg. surface upwelling longwave flux & $\mathrm{Wm}^{-2}$ \\
\hline rsds_avg & domain avg. surface downwelling shortwave flux & $\mathrm{Wm}^{-2}$ \\
\hline rsus_avg & domain avg. surface upwelling shortwave flux & $\mathrm{Wm}^{-2}$ \\
\hline rsdscs_avg & domain avg. surface downwelling shortwave flux - clear sky & $\mathrm{Wm}^{-2}$ \\
\hline rsuscs_avg & domain avg. surface upwelling shortwave flux - clear sky & $\mathrm{Wm}^{-2}$ \\
\hline rldscs_avg & domain avg. surface downwelling longwave flux - clear sky & $\mathrm{Wm}^{-2}$ \\
\hline rluscs_avg & domain avg. surface upwelling longwave flux - clear sky & $\mathrm{Wm}^{-2}$ \\
\hline rsdt_avg & domain avg. TOA incoming shortwave flux & $\mathrm{Wm}^{-2}$ \\
\hline rsut_avg & domain avg. TOA outgoing shortwave flux & $\mathrm{Wm}^{-2}$ \\
\hline rlut_avg & domain avg. TOA outgoing longwave flux & $\mathrm{Wm}^{-2}$ \\
\hline rsutcs_avg & domain avg. TOA outgoing shortwave flux - clear sky & $\mathrm{Wm}^{-2}$ \\
\hline rlutcs_avg & domain avg. TOA outgoing longwave flux - clear sky & $\mathrm{Wm}^{-2}$ \\
\hline
\end{tabular}

For CRMs, the variables should be output on the model levels and on the native $x / y$ grid. For GCMs, the variables should be output on model levels and the native grid (groups may additionally interpolate to the standard CMIP6 pressure levels if they desire). If the native GCM grid is not latitude-longitude, then the output should also be interpolated to a latitudelongitude grid. The output format should be NetCDF, and will be uploaded to a shared data server, which will facilitate analysis and comparison of the simulations.

\subsection{Variables}

Table 4 indicates the list of one-dimensional statistics and domain-averaged profiles that are to be computed and output as hourly averages. The first half of the table includes variables that are profiles (functions of $z$ and $t$ ), while the second half includes variables that are only a function of time. The italicized variables are non-standard outputs; all oth- ers are standard CMIP6 output. The condensed water path, clwvi_avg, includes condensed (liquid plus ice) water, and includes precipitating hydrometeors only if the precipitating hydrometeors affect the calculation of radiative transfer in the model. The ice water path, clivi_avg, includes precipitating frozen hydrometeors only if the precipitating hydrometeors affect the calculation of radiative transfer in the model. The vertical coordinate and time coordinate should also be output. Relative humidity (hur_avg) should be computed with respect to liquid and ice, according to each model's microphysics scheme. We recommend that the Bolton formulation for equivalent potential temperature (thetae_avg) be used (Bolton, 1980, his Eq. 43).

Table 5 indicates the list of two-dimensional variables (functions of $x, y$, and $t$ ) to output as hourly averages. The italicized variables are non-standard outputs; all others are standard CMIP6 output. The starred variables are outputs for 
Table 5. The 2-D hourly-averaged variables $(x, y, t)$.

\begin{tabular}{|c|c|c|}
\hline Variable name & Description & Units \\
\hline $\mathrm{pr}$ & surface precipitation rate & $\mathrm{kg} \mathrm{m}^{-2} \mathrm{~s}^{-1}$ \\
\hline pr_conv! & surface convective precipitation rate & $\mathrm{kg} \mathrm{m}^{-2} \mathrm{~s}^{-1}$ \\
\hline evspsbl & evaporation flux & $\mathrm{kg} \mathrm{m}^{-2} \mathrm{~s}^{-1}$ \\
\hline hfls & surface upward latent heat flux & $\mathrm{Wm}^{-2}$ \\
\hline hfss & surface upward sensible heat flux & $\mathrm{W} \mathrm{m}^{-2}$ \\
\hline rlds & surface downwelling longwave flux & $\mathrm{W} \mathrm{m}^{-2}$ \\
\hline rlus & surface upwelling longwave flux & $\mathrm{W} \mathrm{m}^{-2}$ \\
\hline rsds & surface downwelling shortwave flux & $\mathrm{W} \mathrm{m}^{-2}$ \\
\hline rsus & surface upwelling shortwave flux & $\mathrm{W} \mathrm{m}^{-2}$ \\
\hline rsdscs & surface downwelling shortwave flux - clear sky & $\mathrm{W} \mathrm{m}^{-2}$ \\
\hline rsuscs & surface upwelling shortwave flux - clear sky & $\mathrm{W} \mathrm{m}^{-2}$ \\
\hline rldscs & surface downwelling longwave flux - clear sky & $\mathrm{W} \mathrm{m}^{-2}$ \\
\hline rluscs & surface upwelling longwave flux - clear sky & $\mathrm{W} \mathrm{m}^{-2}$ \\
\hline rsdt & TOA incoming shortwave flux & $\mathrm{W} \mathrm{m}^{-2}$ \\
\hline rsut & TOA outgoing shortwave flux & $\mathrm{W} \mathrm{m}^{-2}$ \\
\hline rlut & TOA outgoing longwave flux & $\mathrm{W} \mathrm{m}^{-2}$ \\
\hline rsutcs & TOA outgoing shortwave flux - clear sky & $\mathrm{W} \mathrm{m}^{-2}$ \\
\hline rlutcs & TOA outgoing longwave flux - clear sky & $\mathrm{W} \mathrm{m}^{-2}$ \\
\hline prw & water vapor path & $\mathrm{kg} \mathrm{m}^{-2}$ \\
\hline clwvi & condensed water path & $\mathrm{kg} \mathrm{m}^{-2}$ \\
\hline clivi & ice water path & $\mathrm{kg} \mathrm{m}^{-2}$ \\
\hline psl & sea level pressure & $\mathrm{Pa}$ \\
\hline tas & $2 \mathrm{~m}$ air temperature & K \\
\hline tabot* & air temperature at lowest model level & $\mathrm{K}$ \\
\hline uas & $10 \mathrm{~m}$ eastward wind & $\mathrm{ms}^{-1}$ \\
\hline vas & $10 \mathrm{~m}$ northward wind & $\mathrm{ms}^{-1}$ \\
\hline uabot* & eastward wind at lowest model level & $\mathrm{ms}^{-1}$ \\
\hline vabot* & northward wind at lowest model level & $\mathrm{ms}^{-1}$ \\
\hline$w a 500^{\wedge}$ & vertical velocity at $500 \mathrm{hPa}$ & $\mathrm{ms}^{-1}$ \\
\hline wap $500^{\sim}$ & omega at $500 \mathrm{hPa}$ & $\mathrm{Pas}^{-1}$ \\
\hline spwr & saturated water vapor path & $\mathrm{kg} \mathrm{m}^{-2}$ \\
\hline $\mathrm{cl}^{!}$ & total cloud fraction of grid column & $\%$ \\
\hline
\end{tabular}

CRMs only. The variables with a (-)! symbol are outputs for GCMs only. Each model should output one or the other of the variables indicated with a symbol, depending on if they are in height $\left({ }^{\wedge}\right)$ or pressure-based $\left({ }^{\sim}\right)$ coordinates. The horizontal coordinates and time coordinate should also be output.

Table 7 indicates the list of three-dimensional variables to output, as instantaneous 6-hourly snapshots. It is optional to upload these variables to the shared data server (we suggest uploading the last 25 days of 3-D output), but the 3-D variables must be saved and stored locally by each modeling group. The italicized variables are non-standard outputs; all others are standard CMIP6 output. The variables with a (-)! symbol are outputs for GCMs only. Note that each model should output omega or vertical velocity, and geopotential height or pressure, depending on whether the model is in pressure-based or height coordinates. Generally, CRMs are in height coordinates and GCMs are in a pressure-based coordinate such as hybrid sigma-pressure levels. Each model should output one or the other of the variables indicated with a symbol, depending on if they are in height $\left(^{\wedge}\right)$ or pressurebased $(\sim)$ coordinates. The horizontal, vertical, and time coordinates should also be output.

\subsection{Diagnostics}

\subsubsection{Cloud fraction}

We request the diagnosis of a global cloud fraction profile that includes all clouds and is the fraction of the entire domain covered by cloud at a given height (it is a function of $z$ and $t$ ). The presence of a cloud should be defined by an appropriate threshold value of cloud condensation (for CRMs, $1 \times 10^{-5} \mathrm{~g} \mathrm{~g}^{-1}$, or $1 \%$ of the saturation mixing ratio over water, whichever is smaller) or output from cloud parameterizations. This variable should be output along with the other 1D variables (Table 4) under the variable name "cldfrac_avg", 
Table 6. The 2-D instantaneous hourly variables $(x, y, t)$.

\begin{tabular}{llll}
\hline Variable name & Description & Units \\
\hline fmse & mass-weighted vertical integral of frozen moist static energy & $\mathrm{Jm} \mathrm{m}^{-2}$ \\
hadvfmse & mass-weighted vertical integral of horizontal advective tendency of frozen moist static energy & $\mathrm{J} \mathrm{m}^{-2} \mathrm{~s}^{-1}$ \\
vadvfmse & mass-weighted vertical integral of vertical advective tendency of frozen moist static energy & $\mathrm{J} \mathrm{m}$ & -2 \\
tnfmse & total tendency of mass-weighted vertical integral of frozen moist static energy & $\mathrm{J} \mathrm{m}^{-2} \mathrm{~s}^{-1}$ & $\mathrm{~J}$ \\
tnfmsevar & total tendency of spatial variance of mass-weighted vertical integral of frozen moist static energy & $\mathrm{J}^{2} \mathrm{~m}^{-4} \mathrm{~s}^{-1}$ \\
\hline
\end{tabular}

Table 7. The 3-D instantaneous hourly variables $(x, y, z, t)$.

\begin{tabular}{|c|c|c|}
\hline Variable name & Description & Units \\
\hline clw & mass fraction of cloud liquid water & $\mathrm{gg}^{-1}$ \\
\hline cli & mass fraction of cloud ice & $\mathrm{gg}^{-1}$ \\
\hline$p l w$ & mass fraction of precipitating liquid water & $\mathrm{gg}^{-1}$ \\
\hline pli & mass fraction of precipitating ice & $\mathrm{gg}^{-1}$ \\
\hline mc! & convective mass flux & $\mathrm{kg} \mathrm{m}^{-2} \mathrm{~s}^{-1}$ \\
\hline ta & air temperature & $\mathrm{K}$ \\
\hline ua & eastward wind & $\mathrm{ms}^{-1}$ \\
\hline va & northward wind & $\mathrm{ms}^{-1}$ \\
\hline hus & specific humidity & $\mathrm{gg}^{-1}$ \\
\hline hur & relative humidity & $\%$ \\
\hline wap $^{\sim}$ & omega & $\mathrm{Pas}^{-1}$ \\
\hline$w a^{\wedge}$ & vertical velocity & $\mathrm{ms}^{-1}$ \\
\hline $\mathrm{zg}^{\sim}$ & geopotential height & $\mathrm{m}$ \\
\hline$p a^{\wedge}$ & pressure & $\mathrm{Pa}$ \\
\hline tntr & tendency of air temperature due to radiative heating & $\mathrm{Ks}^{-1}$ \\
\hline tntc! & tendency of air temperature due to moist convection & $\mathrm{Ks}^{-1}$ \\
\hline tntrs & tendency of air temperature due to shortwave radiative heating & $\mathrm{Ks}^{-1}$ \\
\hline tntrl & tendency of air temperature due to longwave radiative heating & $\mathrm{Ks}^{-1}$ \\
\hline
\end{tabular}

for all simulations. For GCMs, we also request the output of a total cloud fraction for each grid column as a 2-D variable (Table 5) under the variable name "cl", which is a function of $x, y$, and $t$.

\subsubsection{Moist static energy budgets}

We request that each modeling group estimate the moist static energy budget, as accurately as is possible. Specifically, we request the diagnosis and output of the additional 2-D instantaneous variables listed in Table 6. This (along with the other 2-D variables) will enable the quantification of the physical mechanisms related to self-aggregation (using the moist static energy variance budget as in Wing and Emanuel, 2014).

Frozen moist static energy is given by $h=c_{p} T+g z+$ $L_{\mathrm{v}} q+L_{\mathrm{f}} q_{\text {ice. }}$. The values of $c_{p}, g, L_{\mathrm{V}}$, and $L_{\mathrm{f}}$ used by the model formulation should be used to compute $h$. $q_{\text {ice }}$ is the mass fraction of cloud ice. The mass-weighted vertical integral of frozen moist static energy (fmse) is given by

$$
\widehat{h}=\int_{0}^{z_{\text {top }}}\left(c_{p} T+g z+L_{\mathrm{v}} q+L_{\mathrm{f}} q_{\text {ice }}\right) \rho \mathrm{d} z,
$$

or, in pressure coordinates,

$$
\widetilde{h}=\frac{1}{g} \int_{p_{\text {top }}}^{p_{\text {sfc }}}\left(c_{p} T+g z+L_{\mathrm{f}} q_{\text {ice }}\right) \mathrm{d} p .
$$

Care should be taken to make sure the same limits of integration are used at all times/locations. The mass-weighted vertical integral of horizontal advective tendency of frozen moist static energy (hadvfmse) is given by

$$
\int_{0}^{z_{\text {top }}}\left(u \frac{\partial h}{\partial x}+v \frac{\partial h}{\partial y}\right) \rho \mathrm{d} z
$$


and the mass-weighted vertical integral of the vertical advective tendency of frozen moist static energy (vadvfmse) is given by

$$
\int_{0}^{z_{\text {top }}} w \frac{\partial h}{\partial z} \rho \mathrm{d} z
$$

Ideally, frozen moist static energy would be diagnosed online and each model's advection scheme used to advect it, but if this is not possible we ask that groups make their best effort to estimate these terms. The spatial variance of the mass-weighted vertical integral of frozen moist static energy is computed using the squared anomalies from the horizontal mean of the mass-weighted vertical integral of moist static energy $(\widehat{h})$. Its tendency (tnfmsevar) is given by

$$
\frac{\partial}{\partial t}\left(\int_{0}^{z \text { top }} h \rho \mathrm{d} z\right)^{\prime 2}
$$

where' indicates an anomaly from the horizontal mean.

\subsubsection{Aggregation metrics}

We expect that the phenomenon of self-aggregation may occur in some simulations and therefore request the diagnosis of the following metrics that may be used to characterize the degree of aggregation. Code for these (and other) diagnostics will be provided on the RCEMIP website (http: //myweb.fsu.edu/awing/rcemip.html).

1. The "organization index" $\left(I_{\text {org }}\right)$ was introduced by Tompkins and Semie (2017) as an index of aggregation in CRM simulations based on the distribution of nearest neighbor distance between convective entities. If the system exhibits random convection behaving as a Poisson point process, $I_{\text {org }}$ would be equal to 0.5 . Therefore, values of $I_{\text {org }}$ greater than 0.5 indicate aggregated convection, with higher values indicating a higher degree of organization. Tompkins and Semie (2017) used a vertical velocity threshold of $1 \mathrm{~ms}^{-1}$ at $730 \mathrm{hPa}$ to define updraft grid cells in CRM simulations of self-aggregation. Cronin and Wing (2017) compared using a vertical velocity threshold and a cloud top temperature threshold to define $I_{\text {org }}$ in simulations of self-aggregation and found that, while the absolute values of $I_{\text {org }}$ differed, their tendencies were the same. Therefore, given that RCEMIP includes both CRM and GCM simulations and that a vertical velocity threshold may not be appropriate for GCM simulations, here we suggest defining convective grid cells as grid boxes with values of outgoing longwave radiation less than $173 \mathrm{~W} \mathrm{~m}^{-2}$.

2. The "subsidence fraction" (SF) uses the fractional area of the domain covered by large-scale subsidence in the

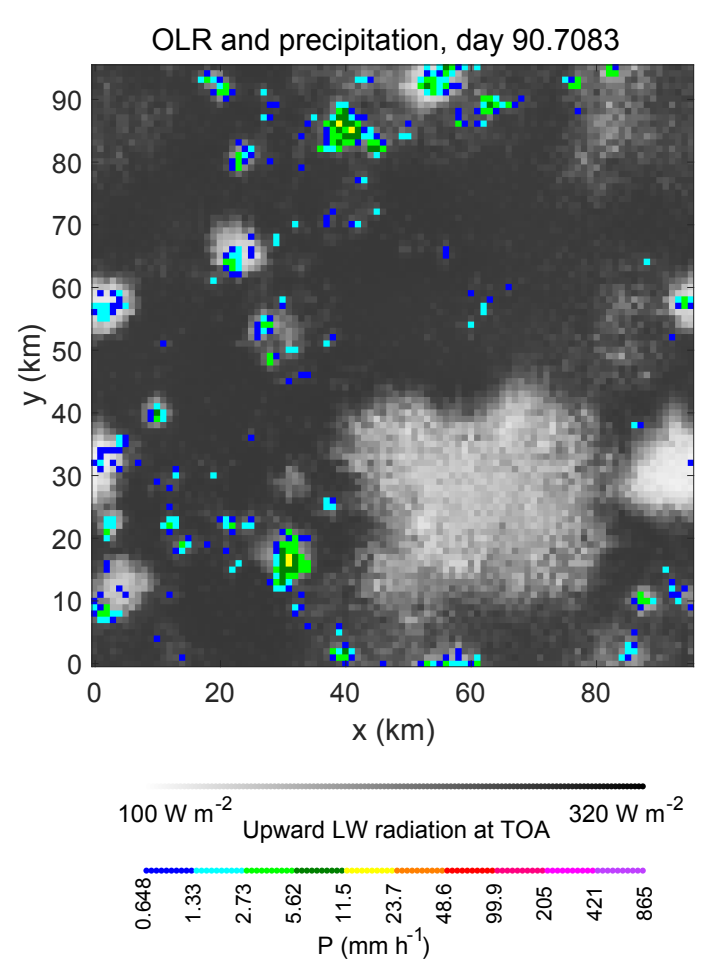

Figure 3. Hourly-average OLR (gray shading) and precipitation (color shading) in small-domain System for Atmospheric Modeling (SAM) simulation at $T_{\mathrm{S}}=300 \mathrm{~K}$.

mid-troposphere $(w<0$ or $\omega>0$ at $500 \mathrm{hPa})$ to characterize the degree of aggregation (Coppin and Bony, 2015). SF is less than 0.6 when convection is unorganized and greater than 0.6 when it is aggregated. For CRM simulations, the vertical velocity at $500 \mathrm{hPa}$ should be averaged over 1 day and over a suitably large area $(\sim 100 \mathrm{~km}$, to approximate the size of a GCM grid cell).

\section{Sample results}

Table 8 shows a preliminary list of models that are confirmed to participate in RCEMIP. We expect this list to grow with participation from other modeling groups and scientists across the world.

Several preliminary simulations using the RCEMIP configuration have been performed using the System for Atmospheric Modeling (SAM), version 6.8.2 (Khairoutdinov and Randall, 2003), a CRM, NICAM, version 15, a GCRM (Satoh et al., 2014), and the Community Atmosphere Model (CAM), version 5 (Neale et al., 2012), a GCM. We show here sample results from those test simulations as an example of what the RCEMIP simulations might look like; this is not intended as a comprehensive comparison. 
Table 8. Preliminary list of participating models.

\begin{tabular}{llll}
\hline Model & Acronym & Model Type & Citation \\
\hline Community Atmosphere Model, version 5 & CAM5 & GCM & Neale et al. (2012) \\
Community Atmosphere Model, version 6 & CAM6 & GCM & TBD \\
ECHAM6 & ECHAM6 & GCM & Popke et al. (2013) \\
ICOsahedral Nonhydrostatic Model & ICON & CRM/GCRM/GCM & Dipankar et al. (2015) \\
IPSL-CM5A-LR & IPSL-CM5A-LR & GCM & Dufresne et al. (2013) \\
IPSL-CM6 & IPSL-CM6 & GCM & TBD \\
Nonhydrostatic ICosahedral Atmospheric Model, & & & \\
version 15 & NICAM.15 & GCRM & Satoh et al. (2014) \\
System for Atmospheric Modeling & SAM & CRM & Khairoutdinov and Randall (2003) \\
UCLA Large-Eddy Simulation Model & UCLA-LES & CRM & Hohenegger and Stevens (2016) \\
\hline
\end{tabular}

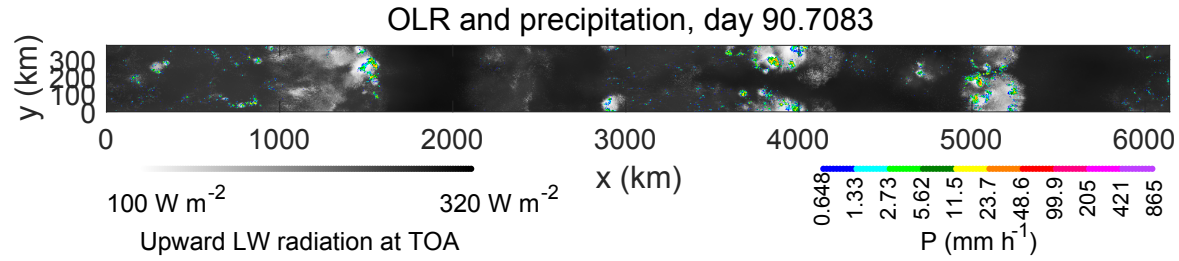

Figure 4. Hourly-average outgoing longwave radiation (gray shading) and precipitation (color shading) in large-domain SAM simulation at $T_{\mathrm{S}}=300 \mathrm{~K}$.
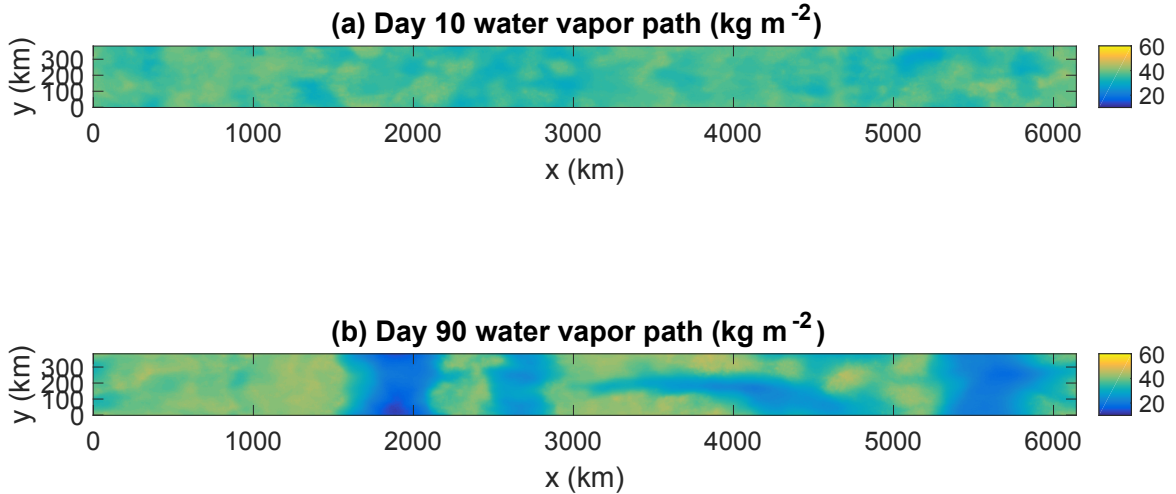

Figure 5. Daily mean water vapor path (computed from hourly averages) on day 10 (a) and day 90 (b) of the large-domain SAM simulation at $T_{\mathrm{S}}=300 \mathrm{~K}$.

Figures 3-7 show example results from a cloud-resolving model simulation of RCE, using SAM with the settings configured as described in Sect. 3.3.1 (with the exception of the $q_{0}$ values in the analytic profiles used to initialize the RCE_small simulations at 295 and $305 \mathrm{~K} ; q_{0}=$ $18.65 \mathrm{~g} \mathrm{~kg}^{-1}$ was used for all simulations shown here). Figure 3 shows outgoing longwave radiation (indicating deep convective clouds) and precipitation rate from the end of a RCE_small simulation at $300 \mathrm{~K}$; the convection is quasirandom in space and time. Figure 4 shows outgoing longwave radiation and precipitation rate from a $\mathrm{RCE}$ _large simulation at $300 \mathrm{~K}$. The convection is aggregated into several large clusters. Self-aggregation is characterized by the development of anomalously moist and dry regions, as can be seen by plots of daily mean water vapor path at day 10 (Fig. 5a) and day 90 (Fig. 5b) of the large-domain SAM simulation. This does not occur in the small-domain simulation (Fig. 6); while the domain dries out slightly, the daily mean water vapor path is spatially homogenous. The moist static energy variance budget can be used to diagnose the physical mechanisms contributing to self-aggregation (Fig. 7). The domain average moist static energy variance increases over 2 orders of magnitude over the course of the simulation, indicating the moistening of moist areas and drying of dry areas (Fig. 7a). Figure 7b shows the contributions of different feed- 

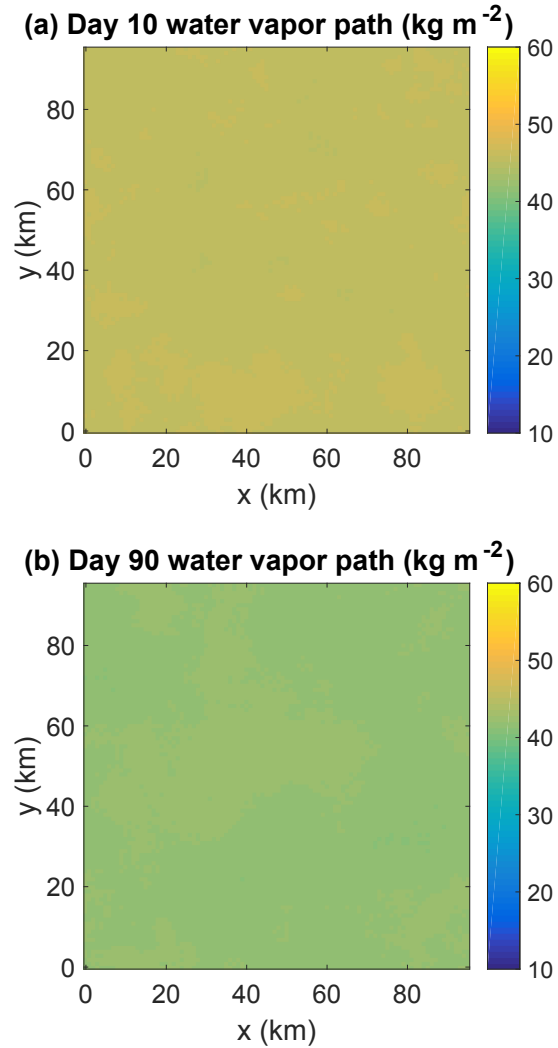

Figure 6. Daily mean water vapor path (computed from hourly averages) on day 10 (a) and day 90 (b) of the small-domain SAM simulation at $T_{\mathrm{S}}=300 \mathrm{~K}$.

backs to that growth in moist static energy variance; in this case, it is the surface flux and longwave radiation feedbacks.

Figure 8 shows an example result from a global simulation of RCE with explicit convection, using NICAM in a global, non-rotating, spherical configuration with a real Earth radius and a $14 \mathrm{~km}$ horizontal grid spacing. Figure 8 shows a snapshot of outgoing longwave radiation (OLR) and precipitation rate, which is similar to Figs. 3-4. The convection has spontaneously organized into clusters. Differences in aggregation properties, such as cluster sizes, can be seen between the results shown in Figs. 4 and 8, which may stem from the domain geometry, the horizontal resolution, or other details, as mentioned in Sect. 3.3.1. Note that, in this example simulation, slightly different values of the solar constant, zenith angle, surface albedo, and minimum wind speed in the surface flux calculation were used than those described in the RCEMIP protocol $\left(434 \mathrm{~W} \mathrm{~m}^{-2}, 0^{\circ}\right.$, and $2 \mathrm{~ms}^{-1}$, respectively). The simulation was initialized from zonally averaged profiles of a coarser-resolution simulation.

Figures 9-10 show example results from a series of GCM simulations of RCE, using CAM5 with the spectral element dynamical core on a cubed-sphere grid with ne 30 resolution, which corresponds to $\sim 100 \mathrm{~km}$ grid spacing. More details on the version of CAM5 (including the physics packages)

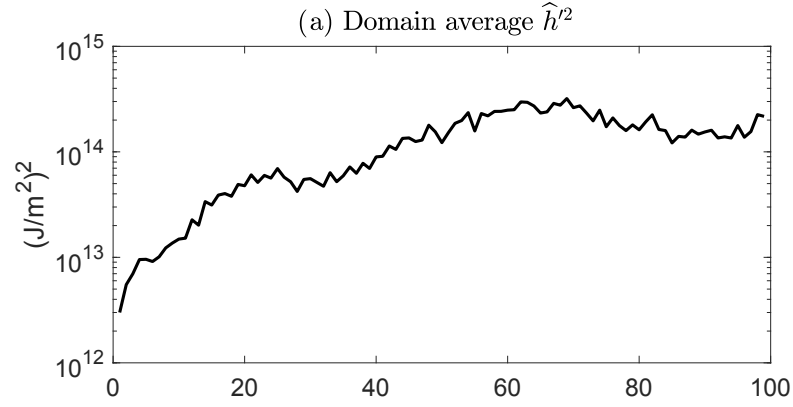

(b) Contributions to growth rate of $\operatorname{var}(\widehat{h})$

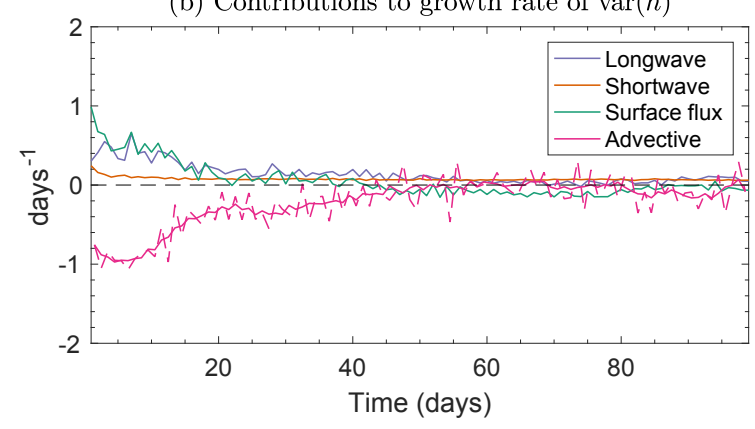

Figure 7. Domain average frozen moist static energy (FMSE) variance (a) and terms in domain average FMSE variance budget, normalized by domain average FMSE variance (b) from the largedomain SAM simulation at $T_{\mathrm{S}}=300 \mathrm{~K}$.

used for these simulations can be found in Reed et al. (2015). Figure 9 shows a snapshot of OLR and precipitation rate for the set of three RCEMIP experiments, which can be compared to Figs. 3, 4, and 8. Figure 10 shows a snapshot of water vapor path (at the same time as displayed in Fig. 9). There is a large cluster of clouds and precipitation in each of the simulations at 300 and $305 \mathrm{~K}$, while the precipitation in the simulation at $295 \mathrm{~K}$ is somewhat more scattered. The simulation at $305 \mathrm{~K}$ appears to be the most aggregated, with a single hemisphere-scale, intensely precipitating cluster and little cloud cover or precipitation elsewhere on the globe. It is also evident from Fig. 10 that the range of water vapor path values is largest in the simulation at $305 \mathrm{~K}$, with the largest values occurring where the clouds and precipitation are clustered.

The above results indicate what RCEMIP simulations might look like in three different model types. Here, we provide a brief example of how the simulations can be compared to each other to determine the robustness of the RCE state and its response to warming across the spectrum of models. One of the objectives of RCEMIP is to examine the changes in clouds with warming. Figure 11 shows that high clouds shift upward with warming and decrease in extent in the SAM and CAM simulations but increase in extent in the NICAM simulations. The decrease in high cloud fraction in the SAM simulations occurs in both the smalland large-domain simulations (without and with convective 


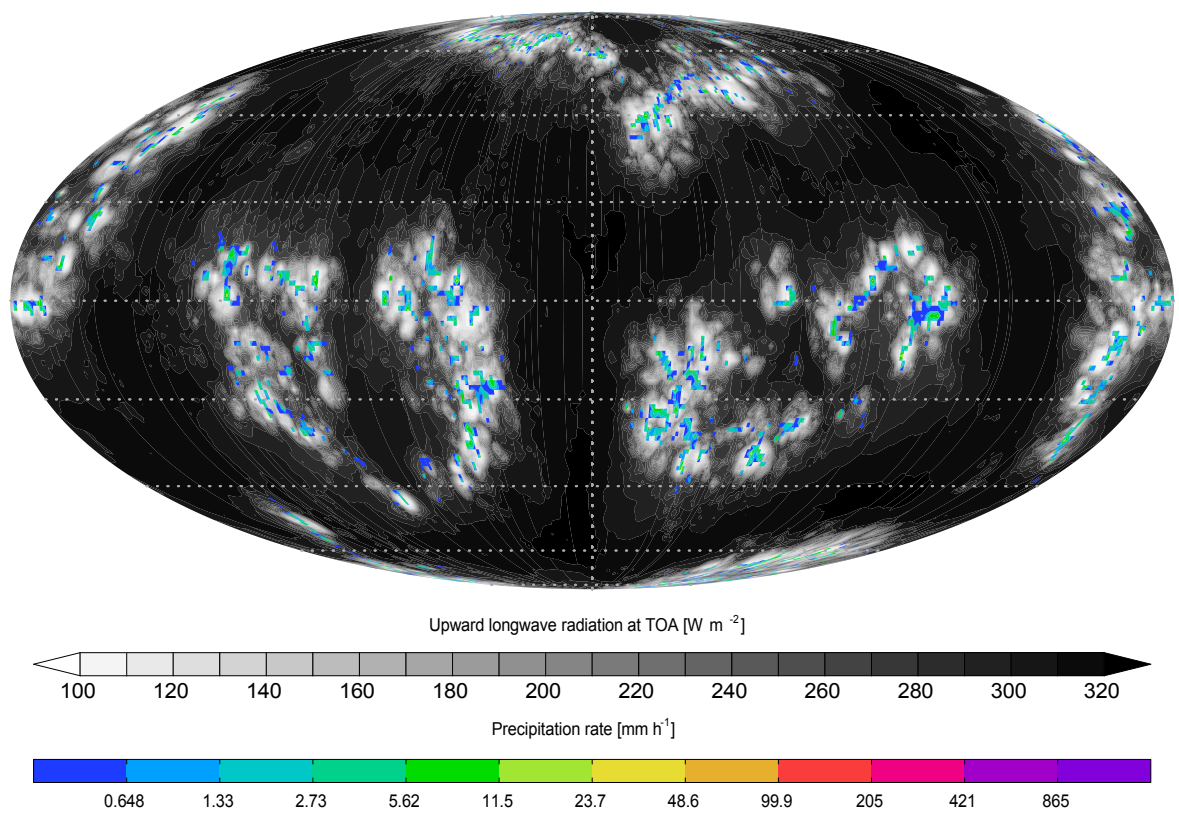

Figure 8. Hourly-averaged OLR at the top of atmosphere (gray shading) and precipitation rate (color shading) in a NICAM simulation at $T_{\mathrm{S}}=300 \mathrm{~K}$. Note that several parameters do not precisely follow the RCEMIP protocol.

aggregation). The degree of convective aggregation can be diagnosed using the subsidence fraction metric, for example (SF; Sect. 4.2.3). In the SAM CRM simulation, the subsidence fraction increases over the first $\sim 40$ days of each simulation, indicating the increasing aggregation of convection and development of large areas of subsiding air (Fig. 12). The mean subsidence fraction over the last 25 days decreases with increasing SST, but there is large variability in the subsidence fraction. The equilibrium value of the subsidence fraction is between $\sim 0.65$ and 0.7 in the SAM simulations, while it is higher $(\sim 0.7-0.8)$ in the NICAM and CAM simulations, indicating that the convection is more aggregated in the global simulations. The subsidence fraction does not depend monotonically on SST in either the NICAM or CAM simulations.

\section{Extensions of RCEMIP}

RCEMIP has been designed to be as simple as possible in order to maximize participation, foster a community of modelers of RCE, and allow for scientific progress on each of our three themes with a minimum of simulations. We recognize that the initial simulations will not necessarily be a definitive representation of the RCE state, for reasons such as lack of boundary closure in some CRMs, distortions of shallow clouds, sensitivity to microphysical formulations, and other sources of bias that we might not be aware of yet. Our vision for the evolution of RCEMIP is that the simulations proposed here serve as a starting point that will allow us to establish a baseline, enable progress on the scientific objectives presented in Sect. 2, and based on the results, in- form subsequent experimentation. RCEMIP presents an exceptional opportunity for the participants to explore other issues, which we hope will form the basis for a second phase of RCEMIP. Here, we provide a few suggestions that we think are promising avenues forward but leave open the possibility for other directions that could evolve from the results of the first RCEMIP simulations.

\subsection{Robustness of RCE results to experimental design}

Additional simulations could be performed to assess the sensitivity of the results to the model setup/configuration (for example, the impact of the lower boundary conditions, dependence on domain size and resolution, and dependence on the initial conditions of convective organization).

\subsection{Sensitivity to the model physics and dynamics}

Additional simulations could be performed to assess the sensitivity to dynamical core, radiation scheme, microphysics scheme, boundary layer scheme, convective scheme (in the case of models with parameterized convection), and the sensitivity to various parameters in those schemes (such as the entrainment parameter in a convective scheme). In some cases, this could be done within a single model, but RCEMIP provides a means of organizing such sensitivity tests across multiple models. For example, a suite of simulations with cloud radiative effects turned off could be performed, which would be useful for comparing the mean state of simulations with explicit convection to that of those with parameterized convection, in the absence of self-aggregation. One promis- 

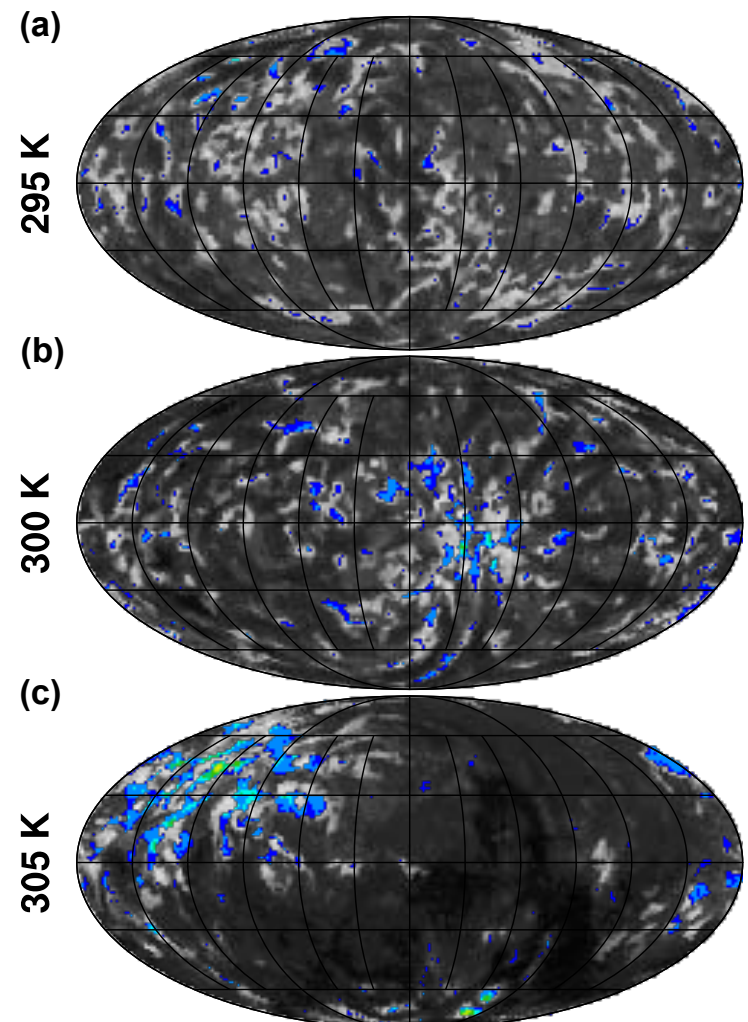

Upward longwave radiation $\left(\mathrm{W} \mathrm{m}^{-2}\right)$
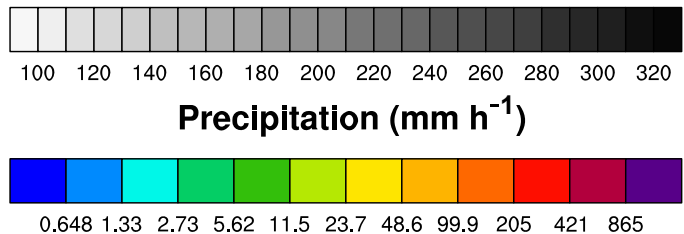

Figure 9. Hourly-averaged snapshot of upward longwave radiation at the top of atmosphere (OLR; gray shading) and precipitation rate (color shading) from the last day (day 1095) of the three CAM simulations at $T_{\mathrm{S}}=295 \mathrm{~K}(\mathbf{a}), T_{\mathrm{S}}=300 \mathrm{~K}(\mathbf{b})$, and $T_{\mathrm{S}}=305 \mathrm{~K}(\mathbf{c})$.

ing avenue forward to determine the sensitivity of the RCE state to model setup, dynamics, and physics is to design unified and simple representations of parameterized processes, as, for instance, was used to study stratocumulus clouds in the GEWEX Cloud System Study (GCSS) intercomparison (Bretherton et al., 1999). Such a setup would reduce the everincreasing complexity of parameterizations and thus may be useful for identifying the origin of differences between models. In particular, we expect large differences to occur based on the diversity in the treatment of microphysics, and because of the neglect of the boundary layer in some CRMs. Jeevanjee et al. (2017), in arguing for an "elegant" RCE configuration, suggested that the adoption of a simple, warmrain, Kessler-type microphysics scheme would ease comparison between models with regards to cloud fraction and cloud radiative effects, for example. Simplified treatments of cloud

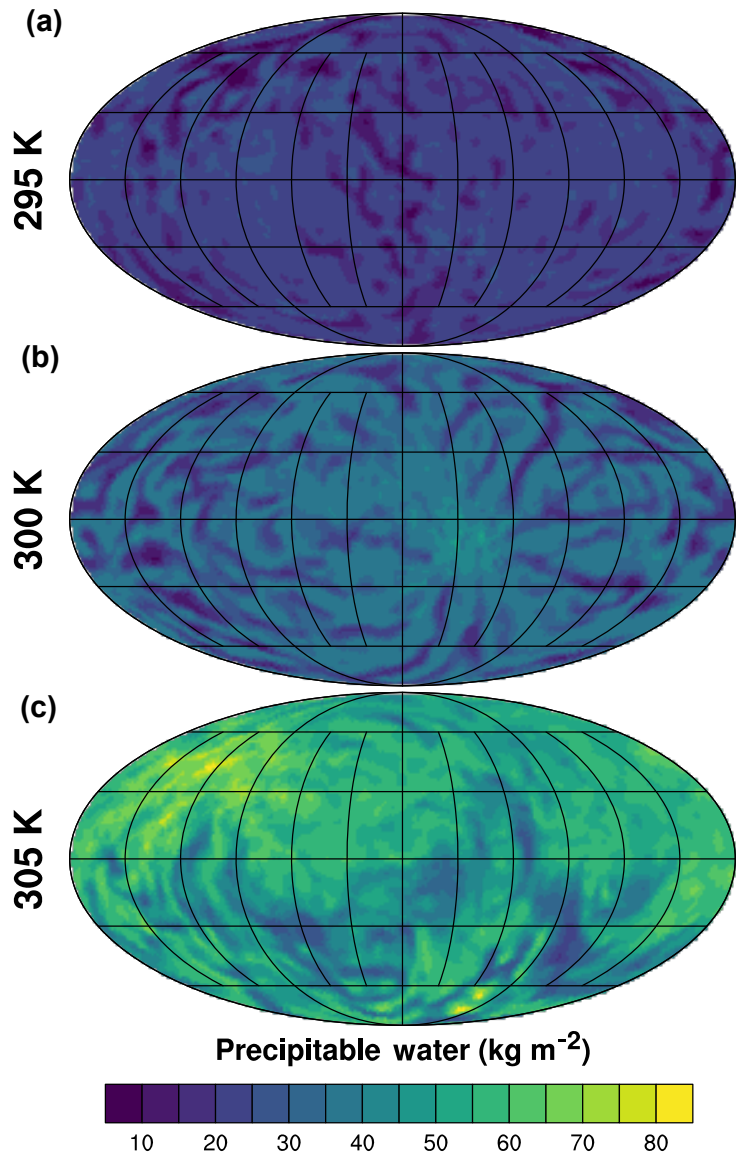

Figure 10. Hourly-averaged water vapor path from the last day (day 1095) of the three CAM simulations at $T_{\mathrm{S}}=295 \mathrm{~K}(\mathbf{a}), T_{\mathrm{S}}=$ $300 \mathrm{~K}(\mathbf{b})$, and $T_{\mathrm{S}}=305 \mathrm{~K}(\mathbf{c})$.

optical properties for radiative transfer and boundary layer closures could also be designed, as could a simple microphysics scheme that includes frozen precipitation.

\subsection{Mechanisms of convective aggregation}

More in-depth investigation into how the mechanisms of convective aggregation vary across models, including their spatial scale and hysteresis, would be valuable. The initial simulations of RCEMIP (Sect. 3) are a good starting point for studying self-aggregation, but further experiments could be defined to leverage the opportunity afforded by RCEMIP to make progress on some of the unanswered questions laid out by Wing et al. (2017). These questions include the behavior of self-aggregation when subjected to mean winds and/or vertical wind shear, simulated over a land surface, or simulated over an ocean mixed layer with interactive SST.

\subsection{Impact of ocean-atmosphere interactions}

The base simulations of RCEMIP (Sect. 3) are atmosphereonly with a fixed SST, but by coupling the atmospheric model 
(a) SAM-Small Domain

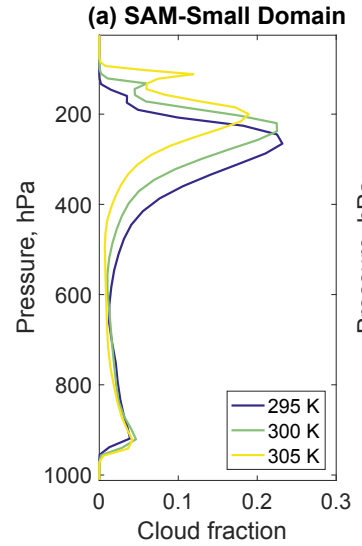

(b) SAM-Large Domain

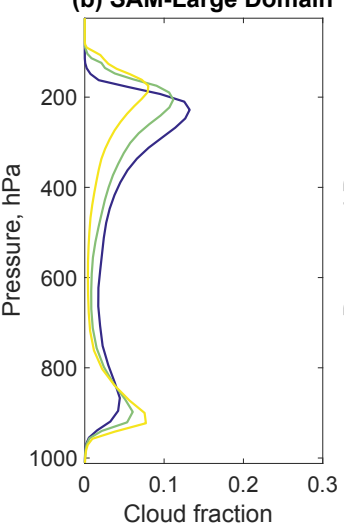

(c) NICAM

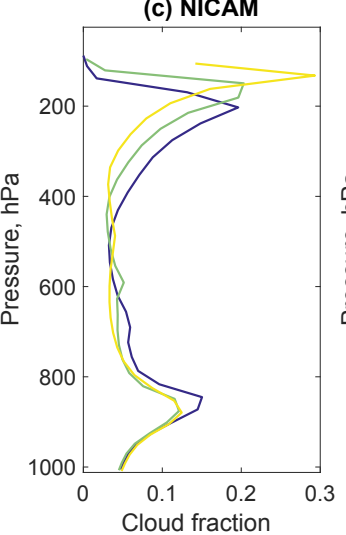

(d) CAM

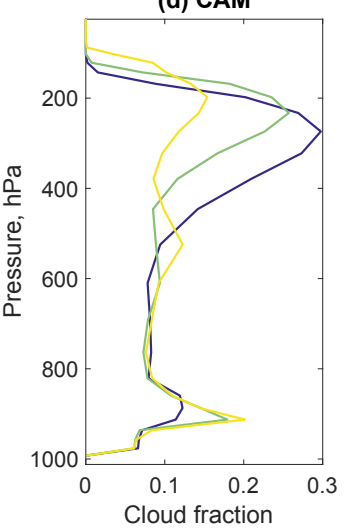

Figure 11. Profiles of total global cloud fraction from the (a) small-domain SAM simulations, (b) large-domain SAM simulations, (c) NICAM simulations, and (d) CAM simulations. The SAM data are averaged over the last 25 days of simulation, the NICAM data are averaged over the last 20 days of simulation, and the CAM data are averaged over the last 2 years of simulation. Note that the NICAM simulations do not precisely follow the RCEMIP protocol, and the NICAM simulations labeled 295 and $305 \mathrm{~K}$ are actually performed at surface temperatures of 296 and $304 \mathrm{~K}$, respectively.
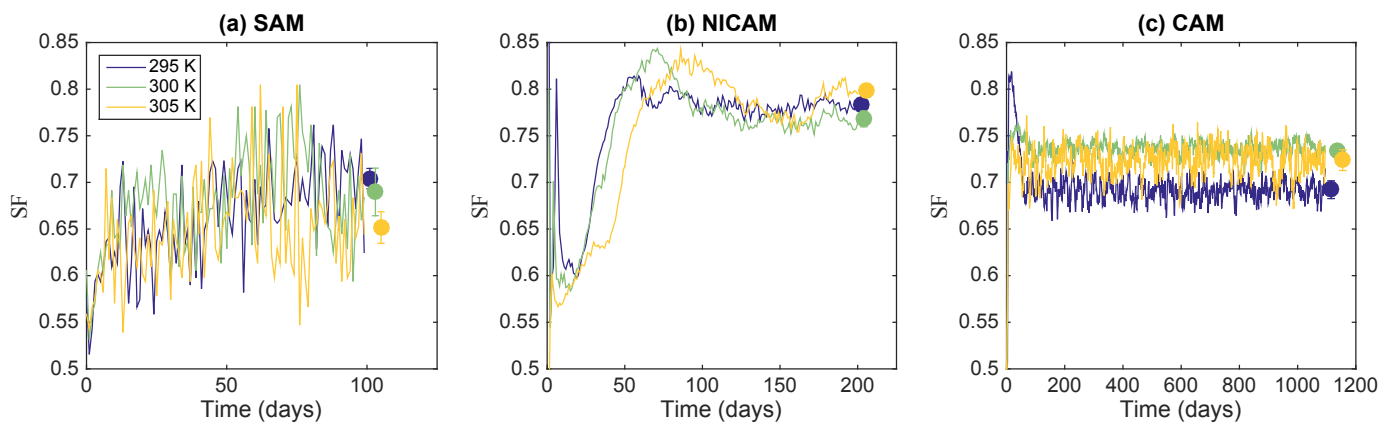

Figure 12. Subsidence fraction ( $\mathrm{SF}$ ) as a function of time in the (a) large-domain SAM simulations, (b) NICAM simulations and (c) CAM simulations. The circles indicate the mean subsidence fraction over the last 25 days of simulation; the error bars indicate the bounds of the 5-95\% confidence interval. Note that the time axes are different in each panel. Also note that the NICAM simulations do not precisely follow the RCEMIP protocol, and the NICAM simulations labeled 295 and $305 \mathrm{~K}$ are actually performed at surface temperatures of 296 and $304 \mathrm{~K}$, respectively.

to an ocean mixed layer, it would be possible to study the influence of air-sea coupling on the interplay between surface temperature and convective aggregation, which has found to be critical in some models (e.g., Coppin and Bony, 2015). An abrupt $4 \times \mathrm{CO}_{2}$ experiment run with such a model would also help assess the RCE response to $\mathrm{CO}_{2}$ forcing, including the adjustment of tropospheric clouds, and the climate sensitivity.

\subsection{Impact of rotation}

RCEMIP has been designed to simulate RCE in a nonrotating framework, but there is a growing body of work simulating rotating RCE, in which convective aggregation takes the form of spontaneous genesis of tropical cyclones (e.g., Held and Zhao, 2008; Khairoutdinov and Emanuel, 2013; Zhou et al., 2014; Shi and Bretherton, 2014; Reed and Chavas, 2015; Wing et al., 2016). Such simulations can be performed on a limited-area domain with uniform rotation, a global domain with uniform rotation, or a global domain with spherically varying rotation.

\section{Conclusions}

Radiative-convective equilibrium is an idealization of the tropical atmosphere that, over the past five decades, has led to advances in our understanding of the vertical temperature structure of the tropics, the scaling of the hydrological cycle with warming, climate sensitivity, interactions between convection and radiation, and the development of large-scale circulations. With a coordinated intercomparison including both cloud-resolving models and general circulation models with parameterized convection, RCEMIP will help answer important questions surrounding changes in clouds and convective activity with warming, cloud feedbacks, and climate 
sensitivity, and the aggregation of convection and its role in climate. In addition, the simple premise of RCE will allow the results of RCEMIP to be connected to theory, as well as serve as a useful framework for model development and evaluation. RCEMIP distinguishes itself from many other intercomparisons because of its ability to involve many model types (SCMs, CRMs, GCRMs, GCMs, LES); the comparison between model types is vital as increasingly higher resolutions are possible in climate-scale global modeling. RCEMIP is specifically designed to determine how models of different types represent the same phenomena and thus provides a basis for testing models with parameterized convection against models that simulate convection directly. In doing so, RCEMIP will help us answer some of the most important questions in climate science.

Code and data availability. Scripts to calculate the analytic sounding described in Sect. 3.2.3 and the diagnostics described in Sect. 4.2 will be available on the RCEMIP website at http://myweb. fsu.edu/awing/rcemip.html. The model output from RCEMIP will be made publicly available through the WDCC/CERA archive at DKRZ, accessible at https://cera-www.dkrz.de/WDCC/ ui/cerasearch/.

Author contributions. AAW led the writing of the text. All authors contributed to editing the text and discussing the goals and specifications of RCEMIP.

Competing interests. The authors declare that they have no conflict of interest.

Acknowledgements. RCEMIP arose from discussion at the Model Hierarchies Workshop, sponsored by the Working Group on Climate Modeling of the World Climate Research Programme and held in Princeton, NJ, in November 2016. The authors thank Nadir Jeevanjee, Timothy Cronin, Kerry Emanuel, George Bryan, and Travis O'Brien for helpful feedback and discussion, as well as Isaac Held, Levi Silvers, and two anonymous reviewers for constructive reviews that improved the design and presentation of RCEMIP. The SAM cloud-resolving model, from which results were shown in Sect. 5, is maintained and provided by Marat Khairoutdinov.

Edited by: Chiel van Heerwaarden

Reviewed by: Levi Silvers, Isaac Held, and two anonymous referees

\section{References}

Arnold, N. P. and Randall, D. A.: Global-scale convective aggregation: implications for the Madden-Julian Oscillation, J. Adv. Model. Earth Syst., 7, 1499-1518, https://doi.org/10.1002/2015MS000498, 2015.

Becker, T. and Stevens, B.: Climate and climate sensitivity to changing $\mathrm{CO}_{2}$ on an idealized land planet, J. Adv. Model. Earth Syst., 6, 1205-1223, https://doi.org/10.1002/2014MS000369, 2014.

Becker, T., Hohenegger, C., and Stevens, B.: Imprint of the convective parameterization and sea-surface temperature on large-scale convective self-aggregation, J. Adv. Model. Earth Syst., 9, 14881505, https://doi.org/10.1002/2016MS000865, 2017.

Bolton, D.: The Computation of equivalent potential temperature, Mon. Weather Rev., 108, 1046-1053, 1980.

Bony, S., Stevens, B., Frierson, D. M. W., Jakob, C., Kageyam, M., Pincus, R., Shepherd, T. G., Sherwood, S. C., Siebesma, A. P., Sobel, A. H., Watanabe, M., and Webb, M. J.: Clouds, circulation and climate sensitivity, Nat. Geosci., 8, 261-268, https://doi.org/10.1038/ngeo2398, 2015.

Bony, S., Stevens, B., Coppin, D., Becker, T., Reed, K. A., Voigt, A., and Medeiros, B.: Thermodynamic control of anvil cloud amount, P. Natl. Acad. Sci. USA, 113, 8927-8932, https://doi.org/10.1073/pnas.1601472113, 2016.

Boucher, O., Randall, D., Artaxo, P., Bretherton, C., Feingold, G., Forster, P., Kerminen, V.-M., Kondo, Y., Liao, H., Lohmann, U., Rasch, P., Satheesh, S., Sherwood, S., Stevens, B., and Zhang, X.: Clouds and aerosols, in: Climate Change 2013: The Physical Science Basis, IPCC, Cambridge Univ. Pres, Cambridge, 571-657, 2013.

Bretherton, C. S., Macvean, M., Bechtold, P., Chlond, A., Cotton, W. R., Cuxart, J., Cuijpers, H., Khairoutdinov, M., Kosovic, B., Lewellen, D., Moeng, C.-H., Siebesma, P., Stevens, B., Stevens, D., Sykes, I., and Wyant, M.: An intercomparison of radiatively-driven entrainment and turbulence in a smoke cloud, as simulated by different numerical models, Q. J. Roy. Meteor. Soc., 125, 391-423, 1999.

Bretherton, C. S., Blossey, P. N., and Khairoutdinov, M.: An energy-balance analysis of deep convective self-aggregation above uniform SST, J. Atmos. Sci., 62, 4237-4292, https://doi.org/10.1175/JAS3614.1, 2005.

Byrne, M. P. and Schneider, T.: Narrowing of the ITCZ in a warming climate: physical mechanisms, Geophys. Res. Lett., 43, 11350-11357, https://doi.org/10.1002/2016GL070396, 2016.

Byrne, M. P. and Schneider, T.: Atmospheric dynamics feedback: concept, simulations and climate implications, J. Climate, https://doi.org/10.1175/JCLI-D-17-0470.1, in press, 2018.

Charney, J. G., Arakawa, A., Baker, D. J., and Bolin, B.: Carbon Dioxide and Climate: A Scientific Assessment, National Research Council, Woods Hole, MA, 1979.

Chavas, D. R. and Emanuel, K. A.: Equilibrium tropical cyclone size in an idealied state of radiative-convective equilibrium, J. Atmos. Sci., 71, 1663-1680, https://doi.org/10.1175/JAS-D-130155.1, 2014.

Claussen, M., Mysak, L., Weaver, A., Crucifix, M., Fichefet, T., Loutre, M.-F., Weber, S., Alcamo, J., Alexeev, V., Berger, A., Calov, R., Ganopolsi, A., Goosse, H., Lohmann, G., Lunkeit, F., Mokhov, I., Petoukhov, V., Stone, P., and Wang, Z.: Earth system models of intermediate complexity: closing the gap in the 
spectrum of climate system models, Clim. Dynam., 18, 579-586, 2002.

Coppin, D. and Bony, S.: Physical mechanisms controlling the initiation of convective self-aggregation in a General Circulation Model, J. Adv. Model. Earth Syst., 7, 2060-2078, https://doi.org/10.1002/2015MS000571, 2015.

Cronin, T. W.: On the choice of average solar zenith angle, J. Atmos. Sci., 71, 2994-3003, https://doi.org/10.1175/JAS-D-13-0392.1, 2014.

Cronin, T. W. and Wing, A. A.: Clouds, circulation, and climate sensitivity in a radiative-convective equilibrium channel model, J. Adv. Model. Earth Syst., 9, 2833-2905, https://doi.org/10.1002/2017MS001111, 2017.

Cronin, T. W., Emanuel, K., and Molnar, P.: Island precipitation enhancement and the diurnal cycle in radiative-convective equilibrium, Q. J. Roy. Meteorol. Soc., 141, 1017-1034, https://doi.org/10.1002/qj.2443, 2015.

Dines, W. H.: The heat balance of the atmosphere, Q. J. Roy. Meteorol. Soc., 43, 151-158, 1917.

Dipankar, A., Stevens, B., Heinze, R., Moseley, C., Zängl, G., Giorgetta, M., and Brdar, S.: Large eddy simulation using the general circulation model ICON, J. Adv. Model. Earth Syst., 7, 963-986, https://doi.org/10.1002/2015MS000431, 2015.

Dufresne, J.-L., Foujols, M.-A., Denvil, S., Caubel, A., Marti, O., Aumont, O., Balkanski, Y., Bekki, S., Bellenger, H., Benshila, R., Bony, S., Bopp, L., Braconnot, P., Brockmann, P., Cadule, P., Cheruy, F., Codron, F., Cozic, A., Cugnet, D., de Noblet, N., Duvel, J.-P., Ethé, C., Fairhead, L., Fichefet, T., Flavoni, S., Friedlingstein, P., Grandpeix, J.-Y., Guez, L., Guilyardi, E., Hauglustaine, D., Hourdin, F., Idelkadi, A., Ghattas, J., Joussaume, S., Kageyama, M., Krinner, G., Labetoulle, S., Lahellec, A., Lefebvre, M.-P., Lefevre, F., Levy, C., Li, Z., Lloyd, J., Lott, F., Madec, G., Mancip, M., Marchand, M., Masson, S., Meurdesoif, Y., Mignot, J., Musat, I., Parouty, S., Polcher, J., Rio, C., Schulz, M., Swingedouw, D., Szopa, S., Talandier, C., Terray, P., Viovy, N., and Vuichard, N.: Climate change projections using the IPSL-CM5 Earth System Model: from CMIP3 to CMIP5, Clim. Dynam., 40, 2123-2165, https://doi.org/10.1007/s00382-012-1636-1, 2013.

Dunion, J.: Rewriting the climatology of the Tropical North Atlantic and Caribbean Sea atmosphere, J. Climate, 24, 893-908, https://doi.org/10.1175/2010JCLI3496.1, 2011.

Emanuel, K., Wing, A. A., and Vincent, E. M.: Radiativeconvective instability, J. Adv. Model. Earth Syst., 6, 75-90, https://doi.org/10.1002/2013MS000270, 2014.

Eyring, V., Bony, S., Meehl, G. A., Senior, C. A., Stevens, B., Stouffer, R. J., and Taylor, K. E.: Overview of the Coupled Model Intercomparison Project Phase 6 (CMIP6) experimental design and organization, Geosci. Model Dev., 9, 1937-1958, https://doi.org/10.5194/gmd-9-1937-2016, 2016.

Grabowski, W., Moncrieff, M., and Kiehl, J.: Long-term behavior of precipitating tropical cloud systems: a numerical study, Q. J. Roy. Meteorol. Soc., 122, 1019-1042, 1996.

Held, I. M. and Zhao, M.: Horizontally homogeneous rotating radiative-covnective equilibrium at GCM resolution, J. Atmos. Sci., 65, 2003-2013, https://doi.org/10.1175/2007JAS2604.1, 2008.
Held, I. M., Hemler, R. S., and Ramaswamy, V.: Radiativeconvective equilibrium with explicity two-dimensional moist convection, J. Atmos. Sci., 50, 3909-3927, 1993.

Held, I. M., Zhao, M., and Wyman, B.: Dynamic radiativeconvective equilibria using GCM column physics, J. Atmos. Sci., 64, 228-238, https://doi.org/10.1175/JAS3825.11, 2007.

Hohenegger, C. and Stevens, B.: Coupled radiative convective equilibrium simulationswith explicit and parameterized convection, J. Adv. Model. Earth Syst., 8, 1468-1482, https://doi.org/10.1002/2016MS000666, 2016.

Holloway, C. E., Wing, A. A., Bony, S., Muller, C., Masunaga, H., L'Ecuyer, T. S., Turner, D. D., and Zuidema, P.: Observing convective aggregation, Surv. Geophys., 38, 1199-1236, 2017.

Ingram, W.: A very simple model for the water vapour feedback on climate change, Q. J. Roy. Meteorol. Soc., 136, 30-40, https://doi.org/10.1002/qj.546, 2010.

Islam, S., Bras, R. L., and Emanuel, K. A.: Predictability of mesoscale rainfall in the tropics, J. Appl. Meteorol., 32, 297310, 1993.

Jeevanjee, N. and Romps, D. M.: Invariant radiative cooling and mean precipitation change, Atmospheric and Oceanic Physics, available at: https://arxiv.org/abs/1711.03516v1, last access: 15 December 2017.

Jeevanjee, N., Hassanzadeh, P., Hill, S. A., and Sheshadri, A.: A perspective on climate model hierarchies, J. Adv. Model. Earth Syst., 9, 1760-1771, https://doi.org/10.1002/2017MS001038, 2017.

Khairoutdinov, M. and Randall, D.: Cloud resolving modeling of the ARM Summer 1997 IOP: model formulation, results, uncertainties, and sensitivities, J. Atmos. Sci., 60, 607-625, 2003.

Khairoutdinov, M. F. and Emanuel, K. A.: Aggregation of convection and the regulation of tropical climate, Preprints, in: 29th Conference on Hurricanes and Tropical Meteorology, Amer. Meteorol. Soc., Tucson, AZ, 2010.

Khairoutdinov, M. F. and Emanuel, K.: Rotating radiativeconvective equilibrium simulated by a cloud-resolving omdel, J. Adv. Model. Earth Syst., 5, 816-825, https://doi.org/10.1002/2013MS000253, 2013.

Manabe, S. and Strickler, R. F.: Thermal equilibriation of the atmosphere with a convective adjustment, J. Atmos. Sci., 21, 361-385, 1964.

Manabe, S. and Wetherald, R. T.: Thermal equilibrium of the atmosphere with a given distribution of relative humidity, J. Atmos. Sci., 24, 241-259, 1967.

Mauritsen, T. and Stevens, B.: Missing iris effect as a possible cause of muted hydrological change and high climate sensitivity in models, Nat. Geosci., 8, 346-351, https://doi.org/10.1038/ngeo2414, 2015.

Möller, F.: On influence of changes in $\mathrm{CO}_{2}$ concentration in air on radiation balance of earths surface and on climate, J. Geophys. Res., 68, 3877-3886, 1963.

Muller, C. J.: Impact of convective organization on the response of tropical precipitation extremes to warming, J. Climate, 26, 50285043, https://doi.org/10.1174/JCLI-D-12-00655.1, 2013.

Muller, C. J. and Held, I. M.: Detailed investigation of the selfaggregation of convection in cloud resovling simulations, J Atmos. Sci., 69, 2551-2565, https://doi.org/10.1175/JAS-D-110257.1, 2012. 
Muller, C. J., O'Gorman, P. A., and Back, L. E.: Intensification of precipitation extremes with warming in a cloud resolving model, J. Climate, 24, 2784-2800, https://doi.org/10.1175/2011JCLI3876.1, 2011.

Nakajima, K. and Matsuno, T.: Numerical experiments concerning the origin of cloud clusters in the tropical atmospheres, J. Meteorol. Soc. Jpn., 66, 309-329, 1988.

Neale, R., Chen, C.-C., Gettelman, A., Lauritzen, P., Park, S., Williamson, D., Conley, A., Garcia, R., Kinnson, D., Lamarque, J.-F., Marsh, D., Mills, M., Smith, A., Tilmes, S., Vitt, F., Morrison, H., Cameron-Smith, P., Collins, W. D., Iacono, M. J., Easter, R. C., Ghan, S. J., Liu, X., Rasch, P. J., and Taylor, M.: Description of the NCAR Community Atmosphere Model (CAM 5.0), NCAR Technical Note NCAR/TM-486+STR, National Center for Atmospheric Research, Boulder, CO, 274 pp., 2012.

Nolan, D. S., Rappin, E. D., and Emanuel, K. E.: Tropical cyclonegenesis sensitivity to environmental parameters in radiativeconvective equilibrium, Q. J. Roy. Meteorol. Soc., 133, 20852107, https://doi.org/10.1002/qj.170, 2007.

Pendergrass, A. G., Reed, K. A., and Medeiros, B.: The link between extreme precipitation and convective organization in a warming climate: Global radiative-convective equilibrium simulations, Geophys. Res. Lett., 43, 11445-11452, https://doi.org/10.1002/2016GL071285, 2016.

Popke, D., Stevens, B., and Voigt, A.: Climate and climate change in a radiative-convective equilibrium version of ECHAM6, J. Adv. Model. Earth Syst., 5, 1-14, https://doi.org/10.1029/2012MS000191, 2013.

Ramanathan, V. and Coakley, J.: Climate modeling through radiative-convective models, Rev. Geophys. Space Ge., 16, 465489, 1978.

Randall, D., Hu, Q., Xu, K.-M., and Krueger, S.: Radiativeconvective disequilibrium, Atmos. Res., 31, 315-327, 1994.

Reed, K. A. and Chavas, D. R.: Uniformly rotating global radiative-convective equilibrium in the Community Atmosphere Model, version 5, J. Adv. Model. Earth Syst., 7, 1938-1955, https://doi.org/10.1002/2015MS000519, 2015.

Reed, K. A., and Jablonowski, C.: An analytic vortex initialization technique for idealized tropical cyclone studies in AGCMs, Mon. Weather Rev., 139, 689-710, https://doi.org/10.1175/2010MWR3488.1, 2011.

Reed, K. A. and Medeiros, B.: A reduced complexity framework to bridge the gap between AGCMs and cloudresolving models, Geophys. Res. Lett., 43, 860-866, https://doi.org/10.1002/2015GL066713, 2016.

Reed, K. A., Medeiros, B., Bacmeister, J. T., and Lauritzen, P. H.: Global radiative-convective equilibrium in the Community Atmosphere Model 5, J. Atmos. Sci., 72, 2183-2197, https://doi.org/10.1175/JAS-D-14-0268.1, 2015.

Renno, N. O., Emanul, K. A., and Stone, P. H.: A radiativeconvective model with an explicit hydrological cycle. Part I: Formulation and sensitivity to model parameters, J. Geophys. Res., 99, 14429-14441, 1994.

Rochetin, N., Lintner, B., Findell, K., Sobel, A., and Gentine, P.: Radiative-convective equilibrium over a land surface, J. Climate, 27, 8611-8629, https://doi.org/10.1175/JCLI-D-1300654.1, 2014.
Romps, D. M.: Response of tropical precipitation to global warming, J. Atmos. Sci., 68, 123-138, https://doi.org/10.1175/2010JAS3542.1, 2011.

Romps, D. M.: An analytical model for tropical relative humidity, J. Climate, 27, 7432-7449, https://doi.org/10.1175/JCLI-D-1400255.1, 2014.

Satoh, M. and Hayashi, Y.-Y.: Simple cumulus models of onedimensional radiative convective equilibrium problems, J. Atmos. Sci., 49, 1202-1220, 1992.

Satoh, M. and Matsuda, Y.: Statistics on high-cloud areas and their sensitivities to cloud microphysics using single-cloud experiments, J. Atmos. Sci, 66, 2659-2677, https://doi.org/10.1175/2009JAS2948.1, 2009.

Satoh, M., Tomita, H., Yashiro, H., Miura, H., Kodama, C., Seiki, T., Noda, A. T., Yamada, Y., Goto, D., Sawada, M., Miyoshi, T., Niwa, Y., Hara, M., Ohno, T., Iga, S.-I., Inoue, T. A. T., and Kubokawa, H.: The Non-hydrostatic ICosahedral Atmospheric Model: description and development, Progr. Earth Planet. Sci., 8, 1-32, https://doi.org/10.1186/s40645-014-0018-1, 2014.

Satoh, M., Arakami, K., and Sawada, M.: Structure of tropical convective systems in aqua-planet experiments: Radiativeconvective equilibrium versus the Earth-like experiments, SOLA, 12, 220-224, 2016.

Seeley, J. T. and Romps, D. M.: Why does tropical convective available potential energy (CAPE) increase with warming?, Geophys. Res. Lett., 42, 10429-10437, https://doi.org/10.1002/2015GL066199, 2015.

Seeley, J. T. and Romps, D. M.: Tropical cloud buoyancy is the same in a world with or without ice, Geophys. Res. Lett., 43, 3572-3579, https://doi.org/10.1002/2016GL068583, 2016.

Shi, X. and Bretherton, C. S.: Large-scale character of an atmospere in rotating radiative-convective equilibrium, J. Adv. Model. Earth Syst., 6, 616-629, https://doi.org/10.1002/2014MS000342, 2014.

Silvers, L. G., Stevens, B., Mauritsen, T., and Giorgetta, M.: Radiative convective equilibrium as a framework for studying the interaction between convection and its large-scale environment, J. Adv. Model. Earth Syst., 8, 1330-1344, https://doi.org/10.1002/2016MS000629, 2016.

Singh, M. and O'Gorman, P.: Influence of entrainment on the thermal stratification in simulations of radiativeconvective equilibrium, Geophys. Res. Lett., 40, 4398-4403, https://doi.org/10.1002/glr.50796, 2013.

Singh, M. and O'Gorman, P.: Influence of microphysics on the scaling of precipitation extremes with temperature, Geophys. Res. Lett., 41, 6037-6044, https://doi.org/10.1002/2014GL061222, 2014.

Singh, M. and O'Gorman, P.: Increases in moist-convective updraft velocities with warming in radiative-convective equilibrium, Q. J. Roy. Meteorol. Soc., 141, 2828-2838, https://doi.org/10.1002/qj.2567, 2015.

Sui, C. H., Lau, K. M., Tao, W. K., and Simpson, J.: The tropical water and energy cycles in a cumulus ensemble model. Part I: Equilibrium climate, J. Atmos. Sci., 51, 711-728, 1994.

Takasuka, D., Miyakawa, T., Satoh, M., and Miura, H.: Topographical effects on the internally produced MJO-like disturbances in an aqua-planet version of NICAM, SOLA, 11, 170176, https://doi.org/10.2151/sola.2015-038, 2015. 
Tan, J., Jakob, C., Rossow, W. B., and Tselioudis, G.: Increases in tropical rainfall driven by changes in frequency of organized deep convection, Nature, 519, 451-454, https://doi.org/10.1038/nature14339, 2015.

Tobin, I., Bony, S., Holloway, C. E., Grandpeix, J. Y., Seze, G., Coppin, D., Woolnough, S. J., and Roca, R.: Does convective aggregation need to be represented in cumulus parameterizations?, J. Adv. Model. Earth Syst., 5, 692-703, https://doi.org/10.1002/jame.20047, 2013.

Tompkins, A. M. and Craig, G.: Radiative-convective equilibrium in a three-dimensional cloud-ensemble model, Q. J. Roy. Meteorol. Soc., 124, 2073-2097, 1998.

Tompkins, A. M. and Semie, A. G.: Organization of tropical convection in low vertical wind shears: Role of updraft entrainment, J. Adv. Model. Earth Syst., 9, 1046-1068, https://doi.org/10.1002/2016MS000802, 2017.

Webb, M. J., Lock, A. P., Bretherton, C. S., Bony, S., Cole, J. N. S., Idelkadi, A., Kang, S. M., Koshiro, T., Kawai, H., Ogura, T., Roehrig, R., Shin, Y., Mauritsen, T., Sherwood, S. S., Vial, J., Watanabe, M., Woelfle, M. D., and Zhao, M.: The impact of parametrized convection on cloud feedback, Philos. T. Roy. Soc. A, 373, 20140414, https://doi.org/10.1098/rsta.2014.0414, 2015.
Wing, A. A. and Cronin, T. W.: Self-aggregation of convection in long channel geometry, Q. J. Roy. Meteorol. Soc., 142, 1-15, https://doi.org/10.1002/qj.2628, 2016.

Wing, A. A. and Emanuel, K. A.: Physical mechanisms controlling self-aggregation of convection in idealized numerical modeling simulations, J. Adv. Model. Earth Syst., 6, 59-74, https://doi.org/10.1002/2013MS000269, 2014.

Wing, A. A., Camargo, S. J., and Sobel, A. H.: Role of radiativeconvective feedbacks in spontaneous tropical cyclogenesis in idealized numerical simulations, J. Atmos. Sci., 73, 2633-2642, https://doi.org/10.1175/JAS-D-15-0380.1, 2016.

Wing, A. A., Emanuel, K., Holloway, C. E., and Muller, C.: Convective self-aggregation in numerical simulations: a review, Surv. Geophys., 38, 1173-1197, https://doi.org/10.1007/s10712-0179408-4, 2017.

Yoshizaki, M., Iga, S., and Satoh, M.: Eastward-propagating property of large-scale precipitation systems simulated in the coarseresolution NICAM and an explanation of its formation, SOLA, 8, 21-24, https://doi.org/10.2151/sola.2012-006, 2012.

Zhou, W., Held, I. M., and Garner, S. T.: Parameter study of tropical cyclones in rotating radiative-convective equilibrium with column physics and resolution of a $25 \mathrm{~km} \mathrm{GC} \mathrm{M.,} \mathrm{J.} \mathrm{Atmos.} \mathrm{Sci.,}$ 71, 1058-1068, https://doi.org/10.1175/JAS-D-13-0190.1, 2014. 